\title{
Estratégias para o setor vitivinícola brasileiro, em contexto global: desenvolvimentos de gestão no Rio Grande do Sul e no Vale do São Francisco
}

\section{Strategies for the Brazilian wine sector, in a global context: management developments in Rio Grande do Sul and the São Francisco Valley}

\author{
PEDRO JORGE PEREIRA RAMALHO \\ ANTÓNIO JOÃO COELHO DE SOUSA \\ JOSÉ LINCOLN PINHEIRO ARAÚJO
}

\section{RESUMO}

Os objetivos deste artigo são: Identificar as estruturas existentes e as estratégias em curso nas empresas vitivinícolas do Rio Grande do Sul e do polo emergente do Vale do São Francisco; identificar e discutir os tipos de reflexões e ações estratégicas que norteiam as decisões nessas empresas; Identificar os impactos ambientais internos e externos nas performances econômicas das empresas; e Formular propostas estratégicas renovadas para uma maior competitividade empresarial. A metodologia utilizada centrou-se numa Grelha Integrada de Reflexão Estratégica para o Brasil (GIRE-br), que inclui um diagnóstico interno e um estudo sistêmico, designado C-A-D, pela articulação das três dimensões

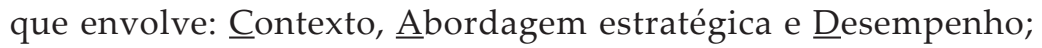
sendo ancorado em análises quantitativas e qualitativas. Foram ainda utilizados o Octógono Estratégico (OE) e a Matriz de Desenvolvimento Empresarial e Operacional Dinâmico (MADED), desenvolvidos originalmente para esta investigação. Os principais 
resultados identificaram três tipos de abordagens estratégicas de perfis diferenciados, um "contra modelo brasileiro" vitivinícola, descompasso entre estratégias e estruturas, baixa atratividade do setor, níveis incipientes de internacionalização, ambição estratégica conservadora, informalidade organizacional marcante e indefinição estratégica.

Palavras-chave: estratégia; vitivinicultura; vinhos; global; Brasil.

\section{AbStract}

The objectives of this article are: To identify the existing structures and ongoing strategies in the vineyard companies from Rio Grande do Sul and from the emerging pole of the São Francisco Valley; to identify and discuss the types of reflections and strategic actions that guide the decisions in these companies; to identify internal and external environmental impacts on business economic performance; and to formulate renewed strategic proposals for greater business competitiveness. The methodology used was based on the Integrated Strategic Reflection Grid for Brazil (GIRE- $b r$ ), which includes an internal diagnosis and a systemic study, named C-A-D, by articulating the three dimensions which involve: Context, Strategic Approach and Performance; being anchored in quantitative and qualitative analyses. The Strategic Octagon (EO) and the Dynamic Business and Operational Development Matrix (MADED) were also used, and were originally developed for this investigation. The main results identify the following: Three types of strategic approaches from differentiated profiles, a "Brazilian counter-model" of vineyards, a mismatch between strategies and structures, low sector attractiveness, incipient levels of internationalization, conservative strategic ambition, remarkable organizational informality and indefinite strategy.

Keywords: strategy; vitiviniculture; wines; global; Brazil.

\section{INTRODUÇÃo}

O grande salto da indústria vitivinícola brasileira deu-se na década setenta, a partir, principalmente, de investimentos estrangeiros no Rio Grande do Sul. Os finais dos anos 90, princípios do novo milênio, marcam o início de um novo ciclo de investimentos, agora em torno da identidade dos vinhos brasileiros. Nos últimos 
anos, vê-se crescer o market share dos vinhos finos, em detrimento dos vinhos indiferenciados. O vinho fino importado detém cerca de $70 \%$ do mercado brasileiro. Em razão desse contexto competitivo em dimensão global, inclusive, algumas questões se impõem: (a) Que estruturas existem e que estratégias estão em curso nas empresas vitivinícolas do Rio Grande do Sul e do Vale do São Francisco? (b) Quais tipos de reflexão/ação estratégica norteiam as decisões estratégico-estruturais dessas empresas? (c) Há diversidade de impactos econômicos nessas empresas, em decorrência das coações ambientais, inclusive, das dinâmicas de internacionalização, e dos tipos de reflexão/ação estratégica empreendidos? (d) Quais são as principais mudanças estratégicas e estruturais que essas empresas necessitam ainda implementar para responderem aos novos desafios e melhorarem a sua competitividade?

São essas as principais questões que orientam o estudo proposto (abrangeu o período 2011 a 2013) e constituem a sua problemática, potencializando a sua importância pelos elementos de resposta que pode proporcionar.

Tendo em atenção o exposto, elege-se, assim, como objetivos deste trabalho:

- Identificar as estruturas existentes e as estratégias em curso nas empresas vitivinícolas do Rio Grande do Sul e do polo emergente do Vale do São Francisco;

- Identificar e discutir os tipos de reflexões e ações estratégicas que norteiam as decisões nessas empresas;

- Identificar os impactos ambientais internos e externos nas performances econômicas das empresas; e

- Formular propostas estratégicas renovadas para uma maior competitividade empresarial.

A realização de um trabalho deste tipo pressupõe a existência de um conjunto de motivações:

- A ausência de estudos sobre essa problemática específica;

- O potencial de desenvolvimento do setor vitivinícola e a sua contribuição em termos econômico-sociais para a duas regiões;

- O caráter oportuno das respostas que um estudo desta natureza pode proporcionar, tendo em conta o período de 
transformação que o setor atravessa, inclusive, em escala global;

- Contribuir com a relação universidade-empresas.

O estudo, portanto, procurou identificar como pensam, decidem e agem os gestores dessas vinícolas brasileiras, bem como oferecer sugestões para uma gestão estratégica renovada. Os resultados mais relevantes apontaram a existência de três tipos de abordagens estratégicas (Adaptativo, Empreendedor e Planejamento Artesanal), um "contra modelo brasileiro" que privilegia os vinhos indiferenciados, um desajuste entre estruturas organizacionais e estratégias, baixa atratividade econômica do setor nas duas regiões, níveis elementares de internacionalização, ambição estratégica conservadora, informalidade organizacional acentuada e ênfase de gestão mais voltada para as operações do que para a estratégia, revelando uma grande indefinição estratégica.

\section{REFERENCIAIS TEÓRICOS E HIPÓTESES}

Do ponto de vista conceptual da estratégia e dos seus principais autores, norteiam este estudo as perspectivas de Sousa (2000), por meio da GIRE-CRP, a racionalidade objetiva e de formalização da Escola do Planejamento Estratégico, de ANSOFF (1990), da maior ou menor subjetividade processual e informalização da Escola Híbrida, com a Análise Estrutural de Indústrias e da Concorrência (PORTER, 1986,1999) e o Modelo de Intenção Estratégica e Polos de Competências (HAMEL; PRAHALAD, 1994).

A emergência da estratégia é igualmente considerada: centrada em horizontes temporais curtos e na grande informalidade de processos (MINTZBERG, 1994; STACEY, 1994) da Escola de Gestão Estratégica.

Esse trabalho, assim, articula abordagens que se estendem da intencionalidade sistêmico- contingente de gestão à emergência das estratégias.

Tendo em atenção, entretanto, as características predominantes do setor vitivinícola, tanto global quanto nacional, esta investigação priorizou uma resposta ao problema de gestão de ANSOFF (1990), 
que pode ser definido como a busca do "equilíbrio de prioridades" entre as decisões estratégicas, administrativas e operacionais. Essa perspectiva teórica alinha-se a Chandler (1962), especificamente ao imperativo de as decisões estratégicas darem origem aos ajustamentos das estruturas orgânicas das empresas (para efeitos operacionais). Galbraith (1977, 2001) e Drucker (1968), entre muitos outros, são autores igualmente âncoras da corrente contingencial.

No cômputo geral, e em nota de advertência sobre as deficiências aferidas por ocasião das avaliações do "equilíbrio de prioridades" das vinícolas do RGS e do VSF, será importante lembrar Ansoff (1990, p. 26), quando ele aponta que: “[...] o ambiente determina as respostas estratégicas e operacionais da empresa e estas, por sua vez, sintonizam com a estrutura de autoridade, responsabilidade, fluxos de trabalho e fluxos de informação dentro da empresa". No que Freire (1997, p. 431) complementa: “[...] é importante um alinhamento dinâmico da estrutura oganizacional com as tendências do meio envolvente, para garantir a coesão a longo prazo entre a estratégia e a estrutura da empresa".

Esses elementos conceptuais e instrumentais foram referências essenciais ao desenvolvimento deste estudo, cuja finalidade foi a de permitir a sua operacionalização, para responder à problemática fixada, aos objetivos pretendidos, bem como à articulação das seguintes hipóteses operativas:

\section{- Hipótese Operativa 1}

As dinâmicas do contexto de internacionalização do setor vitivinícola global induzem mais complexidade e variabilidade ao setor vitivinícola brasileiro e refletem tipos de reflexão estratégica diferenciados;

\section{- Hipótese Operativa 2}

Coações ambientais internas provocam tipos de reflexão estratégica diferenciados, e um comportamento contingente de adaptação estratégica e estrutural;

\section{- Hipótese Operativa 3}

Existe relação entre os tipos de reflexão estratégica e a performance econômica das empresas.

Para testar estas três hipóteses, foi estabelecido um quadro metodológico específico, articulando análises quantitativa e quali- 
tativa com os referenciais teóricos que estão na base das hipóteses de investigação levantadas.

\section{BREVES REFERENCIAIS DO SETOR VITIVINÍCOLA GLOBAL E BRASILEIRO}

O mundo globalizado, cada vez mais integrado economicamente, tem exigido das empresas um grande esforço criativo e inovador. A envolvente empresarial passou por grandes transformações, indo do "fordismo", baseado na produção em massa, até chegar à denominada era do conhecimento, ancorada hoje nas tecnologias de informação (inclui a indústria 4.0 e o big data) e comunicação globalizantes. O excesso estrutural da oferta mundial, as mudanças nas preferências e no comportamento dos consumidores, e a adoção da lógica de produção industrial, pelos produtores do "novo mundo do vinho" (Novos Países Produtores - NPP: EUA, Argentina, Chile, África do Sul, Austrália e Nova Zelândia), estão na origem de muitas dessas mudanças. Esse contexto acabou por levar a indústria a uma recentragem estratégica, por meio de fusões, aquisições e desinvestimentos, tendo resultado na formação de oligopólios concentrados e diversificados (RAMALHO, 2019, 2006; RAMALHO; SOUSA, 2009; RAMALHO; SOUSA, 2011). Para Montaigne (2005), a reestruturação da indústria vitivinícola mundial reflete o fenômeno da "concorrência internacional", numa decorrência da crescente globalização dos mercados.

A indústria vitivinícola brasileira, por sua vez, apresenta um modelo em "contraciclo" ao dos países tradicionais europeus (Gérard Desplobins, 2006), cuja lógica de desenvolvimento é baseada no conceito do "Terroir", bem como em relação aos designados "novos produtores", que atuam sob os modelos de produção industrial de grandes volumes e diversificação especializada. A vitivinicultura brasileira adota um modelo de produção industrial que lhe tem conferido grande estabilidade empresarial, com preponderância da produção de vinhos indiferenciados, de baixa qualidade, elaborados a partir de cepas americanas e híbridas. Entretanto, tem feito alguns avanços importantes nas últimas décadas, em termos de qualidade dos vinhos finos e espumantes. Por outro lado, experimenta dificuldades na sua performance interna e externa, em razão do baixo consumo per capita, intensa concorrência dos vinhos importados, uma indústria mundial estruturalmente excedentária, baixo valor 
de marca nos mercados interno e externo, exigência das economias de escopo necessárias ao enfrentamento de oligopólios globais e um comércio internacional ainda restrito, bem como dificuldades para a internacionalização das suas operações.

\section{Metodologia da investigação}

Para a condução desta investigação foi definido um quadro metodológico rigorosamente delimitado. Neste estudo, a metodologia utilizada inclui uma nova versão da GIRE original: a GIRE-br, aplicada ao Brasil, mas adaptada a uma perspectiva holística da gestão empresarial (estratégia corporativa) do setor vitivinícola. A adaptação inclui ainda a redefinição de algumas variáveis e indicadores a tratar (a exemplo do desempenho econômico), assim como a construção e utilização de instrumentos completamente novos, como é o caso do Octógono Estratégico - Matriz de Desenvolvimento Empresarial Dinâmico (OE-MADED), para enquadrar propostas de decisão e ação estratégica.

É precisamente o conjunto combinado (e não individual) de conceitos, métodos, variáveis, indicadores e instrumentos, e a sua aplicação (adaptada) ao objeto de estudo particular (empresas vitivinícolas brasileiras numa ótica de estratégia corporativa) que vincula a originalidade da metodologia.

Com a definição do quadro conceptual de referência, a vertente empírica utilizou um quadro metodológico em três etapas. A primeira traz o estudo das empresas do Rio Grande do Sul e do Vale do São Francisco, e está inserido no grupo das designadas metodologias empírico-formais ou hipotético-dedutivas (SEKARAN; BOUGIE, 2010, p. 24), de natureza essencialmente quantitativa, com recolha de informação por meio de questionários.

Na investigação das empresas do Vale do São Francisco, para além do método Survey, foi utilizado o Estudo de Caso Múltiplo, com informação recolhida de diversas fontes, desde publicações institucionais do setor, até aos próprios empresários, por meio da implementação de questionários e entrevistas semi-estruturadas. A segunda etapa da investigação traz a aplicação da ferramenta operacional e integrada de abordagem estratégica construída para esta pesquisa - a Grelha Integrada de Reflexão Estratégica para a indústria vitivinícola brasileira (GIRE-br). 
Figura 1. GIRE(br): Estrutura global e lógicas de abordagem

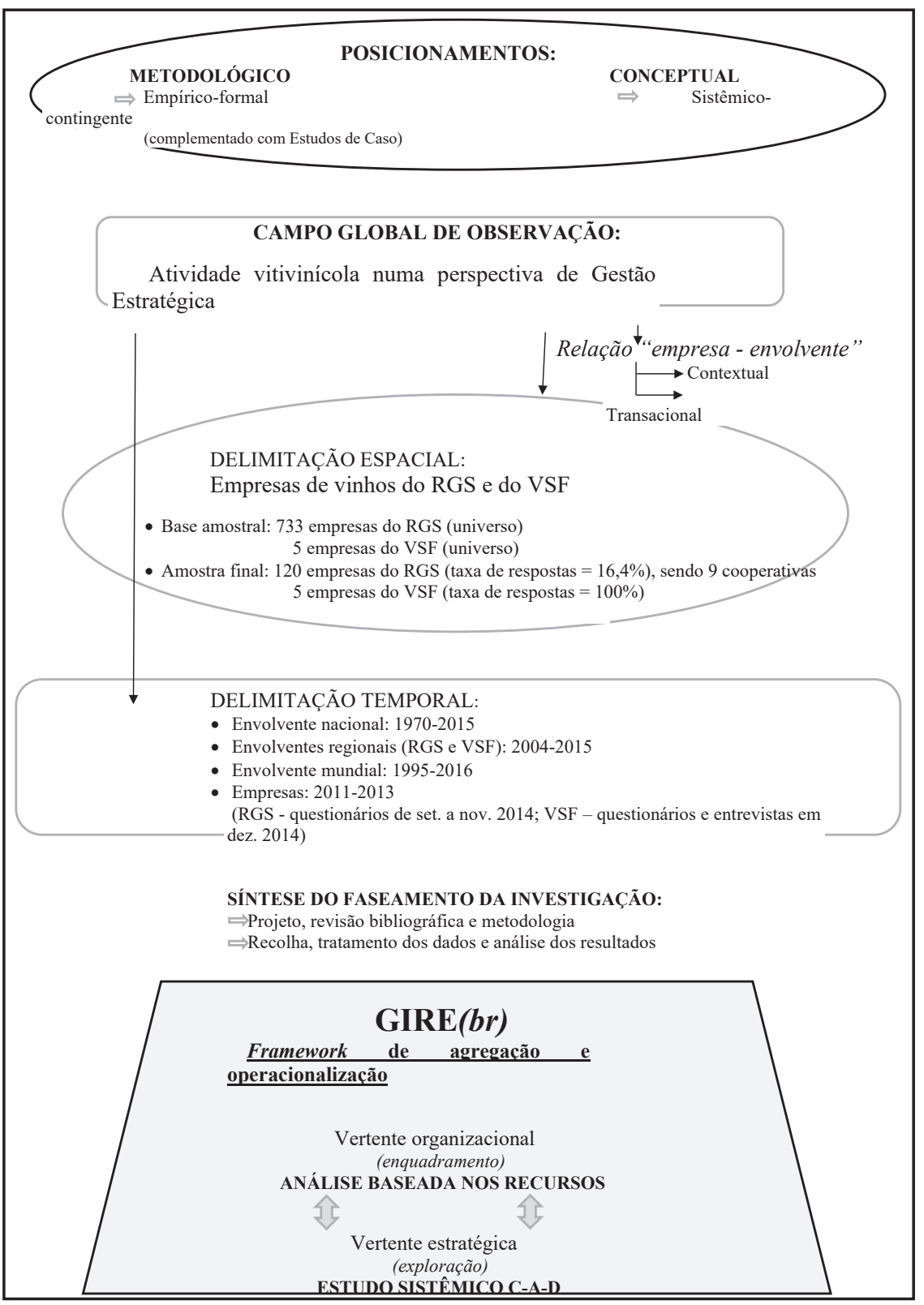

Fonte: Adaptado de Sousa (2000). 
De referir que esta Grelha propõe um quadro metodológico específico que começa com um diagnóstico da vertente organizacional das empresas (seguindo a lógica da análise baseada nos recursos) para, depois, explorar a vertente estratégica das mesmas através de um estudo sistêmico, designado C-A-D pela articulação das três

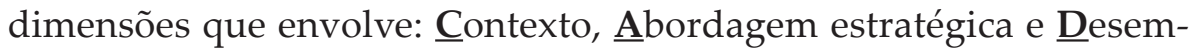
penho. Utiliza para o efeito diversas variáveis e indicadores que, uma vez trabalhadas por meio de análises quantitativas e qualitativas, permitem testar as três hipóteses operacionais da investigação.

Figura 2. Modelo conceptual de base

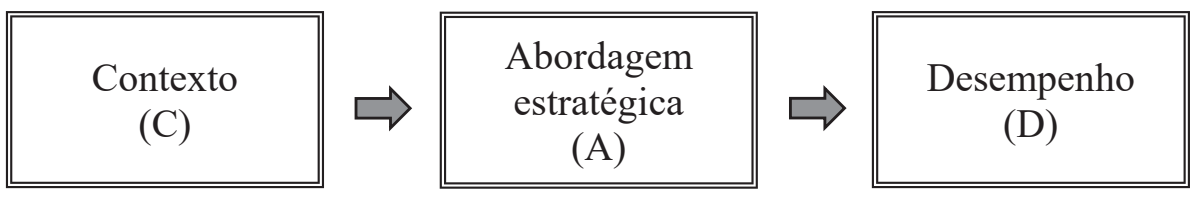

Fonte: elaboração própria.

Para identificar os tipos de abordagens estratégicas por grupos de empresas é feita, em primeiro lugar, uma análise exploratória dos dados recolhidos por meio de questionário e, na sequência, é realizada uma Análise Fatorial em Componentes Principais (ACP) para confirmar a independência dos dois fatores (formalização e antecipação) que estão na base dos diferentes tipos de abordagens estratégicas.

O estudo exploratório das variáveis permitiu aferir, também, a simetria da distribuição de cada variável utilizada e verificar a existência de outliers e de não respostas (missing values), de forma a garantir que essas variáveis (questões específicas do questionário) não apresentassem problemas graves de enviesamento e, dessa maneira, não viessem a invalidar os resultados apurados pela análise fatorial.

No estudo de simetria foram utilizados os procedimentos de Análise (Descriptive Statistics Explore), disponíveis no software estatístico SPSS utilizado. As estatísticas descritivas das 4 variáveis utilizadas para medir o processo de abordagem estratégica das empresas, permitem constatar que a amostra é composta por 125 
respondentes, não registrando quaisquer missing values, ou seja, nenhum dos respondentes omitiu respostas, razão pela qual todos os casos são considerados válidos para a análise. Verifica-se, também, que a média das 4 variáveis estão só muito levemente afastadas (situam-se entre 3,50 e 3,74), sendo a sua dispersão moderada (entre 0,858, e 1,014). Esta ocorrência associada ao resultado do quociente de assimetria, dado pelo quociente entre Skewness (assimetria) e Std. Error (erro padrão) leva-nos a concluir que a maioria das variáveis em análise apresenta uma distribuição simétrica.

No que diz respeito à normalidade das distribuições, foram utilizados os testes de Kolmogorov-Smirnov (K-S) e Shapiro-Wilks $(S-W)$. Os resultados destes testes confirmam que nenhuma das 4 variáveis analisadas tem distribuição normal. Naturalmente que a não normalidade da distribuição não anula a inclusão de todas as variáveis na ACP, uma vez que se pode recorrer ao Teorema do Limite Central, dada a dimensão ( $\mathrm{n}>30$; neste caso 125) da amostra (PESTANA e GAGEIRO, 2008). Então, pelo fato de a amostra ter uma dimensão acima de 30 elementos, optou-se por aplicar efetivamente o teorema, assumindo-se que a distribuição tende para a normalidade, pois, à medida que o tamanho " $n$ " da amostra aumenta, a distribuição das médias amostrais tende para uma distribuição normal (MAROCO, 2007; PESTANA; GAGEIRO, 2007). Foi utilizada, ainda, uma Análise Discriminante (AD) com o objetivo de confirmar os resultados da Análise Fatorial em Componente Principal (ACP) e da Análise de Clusters (AC). O processo procura validar os 3 clusters extraídos da AC e, ainda, confirmar o poder de discriminação dos 2 fatores (Antecipação e Formalização) retidos pela $\mathrm{ACP}$.

A aplicação da $\mathrm{AD}$ tem como pressupostos a normalidade e a homogeneidade das matrizes de variâncias-covariâncias. Para além disso, destaca-se que, sendo a AD uma técnica estatística vigorosa e resistente a violações de normalidade, ela foi mantida com a totalidade das variáveis.

Para verificar a homogeneidade da matriz de variâncias-covariâncias, aplicou-se o teste $M$ de Box. Dado que este teste tem associado um nível de significância de 0,047, pode-se concluir que ele só é válido para um $\alpha=0,05$, ou seja, com a igualdade das dis- 
persões entre os clusters, qualquer que seja o erro tipo I do analista para um $\alpha=0,05$.

A matriz de covariâncias e de correlações (Pooled Within-Groups Matrices) comprova que a correlação é negativa, implicando, consequentemente, maior grau de antecipação, que resulta em menor grau de formalização $(-0,171)$ e vice-versa. Esse resultado robustece o vigor do modelo em análise.

Para além disso, importa ter presente que, se a normalidade da distribuição é um pressuposto exigido para o método da máxima verosimilhança, não o é para o método das componentes principais (PESTANA; GAGEIRO, 2005, p. 488).

Destaca-se, ainda, que o Alpha de Cronbach é de 0,757, pelo que se pode deduzir que a fiabilidade ou coerência interna, das 4 variáveis, é satisfatória. É um dos indicadores mais utilizados para medir a consistência interna das variáveis utilizadas, definindo-se concretamente como "[..] a correlação que se espera obter entre a escala utilizada e outras escalas hipotéticas do mesmo universo, com igual número de itens, para medir a mesma característica". Este indicador varia entre 0 e 1, considerando-se a consistência interna como razoável para valores de alpha entre 0,7 e 0,8 (PESTANA; GAGEIRO, 2008, p. 528).

Todo este conjunto de resultados comprovam que as variáveis utilizadas apresentam consistência interna, podendo ser utilizadas nas análises ACP e de clusters para identificação e composição de grupos homogêneos de empresas (por tipo de abordagem estratégica).

Feita a Análise de Clusters (AC) para proceder ao agrupamento das empresas e uma Análise Discriminante (AD) para confirmar os resultados da ACP e da AC, a Tabela 1 (abaixo) evidencia a constituição dos 3 clusters de empresas encontrados e a sua disposição relativamente a cada fator (antecipação e formalização). 
Tabela 1. Caraterísticas dos tipos de abordagens estratégicas: resultados das análises estatísticas

\begin{tabular}{|c|c|c|c|c|c|c|c|}
\hline Fatores & Clusters & $\mathrm{N}$ & $\%$ & Média & $\begin{array}{l}\text { Desvio } \\
\text { Padrão }\end{array}$ & $\begin{array}{l}\text { Ano- } \\
\text { va } \\
\text { (Sig.) }\end{array}$ & $\begin{array}{l}\text { Comparação entre } \\
\text { os grupos (Sheffé } \\
\text { test) }\end{array}$ \\
\hline \multirow{3}{*}{$\begin{array}{c}\text { Grau de } \\
\text { Antecipação }\end{array}$} & Empreendedor & 52 & $41,60 \%$ & $-0,8503109$ & 0,67626058 & \multirow{3}{*}{0,000} & \multirow{3}{*}{$\begin{array}{c}\mathrm{AD}>\mathrm{EM}^{* * *} ; \mathrm{PA}> \\
\mathrm{EM}^{* * * *} \frac{\text { Homogeneous }}{\underline{\text { Subsets }}}\end{array}$} \\
\hline & Adaptativo & 62 & $49,60 \%$ & 0,5367129 & 0,71514780 & & \\
\hline & P. Artesanal & 11 & $8,80 \%$ & 0,9945423 & 0,56045731 & & \\
\hline \multirow{3}{*}{$\begin{array}{c}\text { Grau de } \\
\text { Formalização }\end{array}$} & Empreendedor & 52 & $41,60 \%$ & $-0,2733768$ & 0,73228199 & \multirow{3}{*}{0,000} & \multirow{3}{*}{$\begin{array}{c}\mathrm{EM}>\mathrm{PA}{ }^{* * * *} ; \mathrm{AD}>\mathrm{EM} \\
\mathrm{AD}>\mathrm{PA} * * * \\
\underline{\text { Homogeneous }} \\
\underline{\text { Subsets }}\end{array}$} \\
\hline & Adaptativo & 62 & $49,60 \%$ & 0,5849033 & 0,58912652 & & \\
\hline & P. Artesanal & 11 & $8,80 \%$ & $-2,0044010$ & 0,78674238 & & \\
\hline
\end{tabular}

Fonte: Elaboração própria, baseada nos outputs da ANOVA e do Post Hoc Tests - SPSS

*** Sig. $<0,01$.

Ao nível da estratégia empresarial, é feita uma análise do macroambiente e do microambiente de negócios. É também realizada uma análise interna, ou seja, dos recursos e competências das empresas estudadas.

A terceira etapa da pesquisa envolveu a aplicação do Octógono Estratégico e Matriz de Desenvolvimento Empresarial Dinâmico (OE-MADED), também desenhados especificamente para enquadrar os oito corredores de decisão e ação estratégica recomendados no âmbito deste estudo (ver as figura 3 e 4, mais adiante).

A recolha de dados com base na amostra probabilística de corte-transversal (cross-sectional), para as empresas do Rio Grande do Sul e do VSF, é feita por questionário, pessoalmente implementado em campo aos seus dirigentes de topo. Os dados dele resultantes são objeto de tratamento por meio de estatísticas univariadas, bivariadas e multivariadas.

Foram também utilizadas algumas análises essencialmente qualitativas (para diagnosticar o grau de complexidade que é aferido pelo número de atores ou de variáveis e respectivas relações.) e a variabilidade setorial (é medida pelas variações frequentes e/ ou amplas que caracterizam os ambientes externos às empresas), 
notadamente os métodos PEST (evidencia os quatro contextos a diagnosticar: o Político-legal, o Econômico, o Sócio-Cultural e o Tecnológico-Científico), das cinco forças competitivas, entre outros.

Para finalizar, convém salientar que estamos perante um quadro metodológico consistente e confiável, uma vez que a GIRE (concebida por Sousa, 2000, com inspiração nos trabalhos de Calori et al., 1997, sobre o planejamento estratégico de pequenas e médias empresas) já foi originalmente testada e utilizada nas abordagens estratégicas de empresas vitivinícolas de duas regiões específicas (Alentejo e Extremadura espanhola) e, posteriormente, aplicada, em versões adaptadas a espaços geográficos distintos: Portugal e Brasil, respectivamente, numa perspectiva de internacionalização empresarial GIRE- $i$ (adaptação feita nos trabalhos de VIVAS, 2012) e de gestão da inovação GIREinov (RAMOS, 2015), e, ainda, GIRE-br, de gestão (holistica) (RAMALHO, 2019), sempre no mesmo setor de atividade, o setor vitivinícola.

\subsection{OE-Maded - Uma ferramenta de definição dos corredo- res estratégicos de decisão}

O OE-MADED é a ferramenta metodológica concebida para enquadrar, numa estrutura de oito grandes dimensões estratégicas, o conjunto de decisões que consubstanciam propostas de ações concretas para melhorar a competitividade das empresas e do setor, tendo por base, por um lado, a percepção dos empresários sobre o posicionamento das suas respectivas empresas nessas dimensões estratégicas (através da análise das respostas dadas às questões específicas do questionário, realizada por meio de estatísticas descritivas) e, por outro lado, a síntese das recomendações estratégicas feitas numa lógica de manobras estratégicas da SWOT MATRIX (WEIHRICH, 1982). As propostas estratégicas referidas nesse artigo, decorrentes deste estudo, estão materializadas nas considerações finais.

Essas oito dimensões de decisão e sua operacionalização estão sintetizadas nas figuras 3 e 4 : 
Figura 3. O Octógono Estratégico e as oito dimensões de decisão estratégica

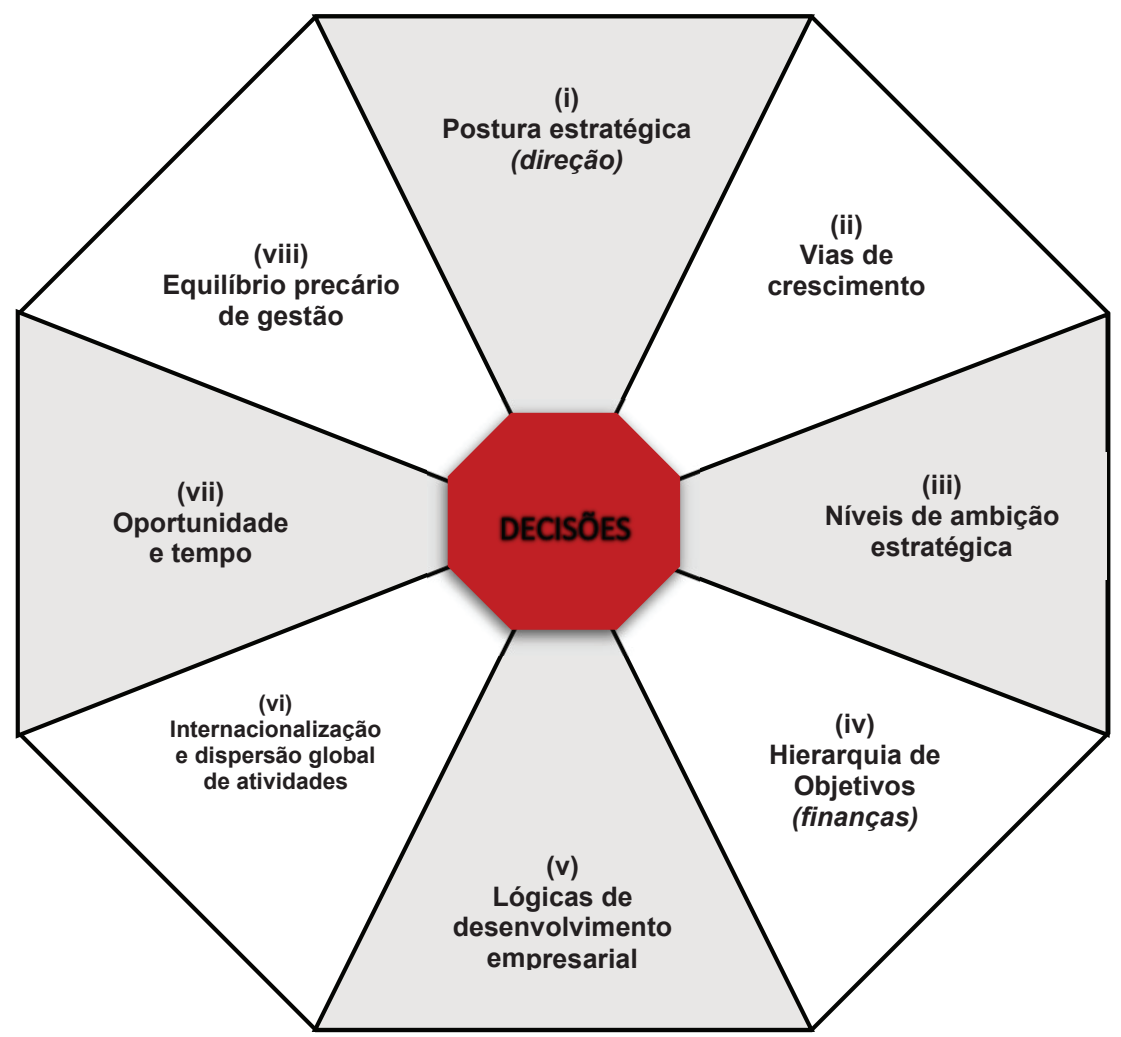

Fonte: Elaboração própria.

É sobre estes oito corredores estratégicos que as empresas se devem concentrar para ganharem competitividade acrescida. É com foco neles que são decididas as propostas de ação empresarial para manter e/ou ampliar posições relativas das empresas e do próprio setor vitivinícola brasileiro, no mundo. 
ESTRATÉGIAS PARA O SETOR VITIVINÍCOLA BRASILEIRO, EM CONTEXTO GLOBAL: desenvolvimentos de gestão no Rio Grande do Sul e no Vale do São Francisco

Figura 4. A ferramenta metodológica OE-MADED

\section{OE-MADED}

\section{Octógono Estratégico (OE)}

\begin{tabular}{|c|c|c|c|c|c|c|c|}
\hline $\begin{array}{l}\text { (i) } \\
\text { Postura } \\
\text { Estratégica } \\
\text { (direção) }\end{array}$ & $\begin{array}{l}\text { (ii) } \\
\text { Vias de } \\
\text { Cresci- } \\
\text { mento }\end{array}$ & $\begin{array}{l}\text { (iii) } \\
\text { Níveis de } \\
\text { Ambição } \\
\text { Estratégica }\end{array}$ & $\begin{array}{l}\text { (iv) } \\
\text { Hierarquia } \\
\text { de Objetivos } \\
\text { (finanças) }\end{array}$ & $\begin{array}{l}\text { (v) } \\
\text { Lógicas Estraté- } \\
\text { gico- } \\
\text { Empresariais }\end{array}$ & $\begin{array}{l}\text { (vi) } \\
\text { Internacionali- } \\
\text { zação e Disper- } \\
\text { são Global de } \\
\text { Atividades } \\
\text { (bases domés- } \\
\text { ticas) }\end{array}$ & $\begin{array}{l}\text { (vii) } \\
\text { Oportunidade e } \\
\text { Tempo }\end{array}$ & $\begin{array}{l}\text { (viii) } \\
\text { Equilíbrio de } \\
\text { Gestão }\end{array}$ \\
\hline $\begin{array}{l}\text { (CE1-PE) } \\
\text { REFEREN- } \\
\text { CIAS } \\
\text { DE DECI- } \\
\text { SÃO: }\end{array}$ & $\begin{array}{l}\text { (CE2-VC) } \\
\text { REFEREN- } \\
\text { CIAS } \\
\text { DE DECI- } \\
\text { SÃO: }\end{array}$ & $\begin{array}{l}\text { (CE3-NAE) } \\
\text { REFEREN- } \\
\text { CIAS } \\
\text { DE DECI- } \\
\text { SÃO: }\end{array}$ & $\begin{array}{l}\text { (CE4-HO) } \\
\text { REFEREN- } \\
\text { CIAS } \\
\text { DE DECI- } \\
\text { SÃO: }\end{array}$ & $\begin{array}{l}\text { (CE5-LEE) REFE- } \\
\text { RENCIAS } \\
\text { DE DECISÃO: }\end{array}$ & $\begin{array}{l}\text { (CE6-IDGA) } \\
\text { REFERENCIAS } \\
\text { DE DECISÃO: }\end{array}$ & $\begin{array}{l}\text { (CE7-OT) } \\
\text { REFERENCIAS } \\
\text { DE DECISÃO: }\end{array}$ & $\begin{array}{l}\text { (CE8-EG) } \\
\text { REFEREN- } \\
\text { CIAS } \\
\text { DE DECISÃO: }\end{array}$ \\
\hline $\begin{array}{l}\text { - Sobrevi- } \\
\text { vência; } \\
\text { - Manuten- } \\
\text { ção; } \\
\text { - Cresci- } \\
\text { mento; } \\
\text { - Desenvol- } \\
\text { vimento. }\end{array}$ & $\begin{array}{l}\text { - Interna; } \\
\text { - Externa; } \\
\text { - Mista. }\end{array}$ & $\begin{array}{l}\text {-Onde com- } \\
\text { petir (espaços } \\
\text { e portfólio); } \\
\text { - Como } \\
\text { competir } \\
\text { (estratégias } \\
\text { de negócio e } \\
\text { competitiva). }\end{array}$ & $\begin{array}{l}\text {-Recursos } \\
\text { econômicos } \\
\text { e financeiros: } \\
\text { imediatis- } \\
\text { mo versus } \\
\text { sustentabili- } \\
\text { dade } \\
\text { (foco na } \\
\text { liquidez ou na } \\
\text { rentabilidade). }\end{array}$ & $\begin{array}{l}\text {-Estratégia corpo- } \\
\text { rativa (diversifi- } \\
\text { cação): } \\
\text { Relacionada } \\
\text { (vertical, horizontal } \\
\text { e concêntrica) ou } \\
\text { Não Relacionada } \\
\text { (conglomerada); } \\
\text { - Estratégia de } \\
\text { negócios } \\
\text { (produtos-mercados, } \\
\text { integração vertical } \\
\text { e internacionali- } \\
\text { zação). }\end{array}$ & $\begin{array}{l}\text { - Localização } \\
\text { que concentra } \\
\text { geograficamente } \\
\text { a vantagem } \\
\text { competitiva; } \\
\text { - Fontes de } \\
\text { vantagem com- } \\
\text { petitiva. }\end{array}$ & $\begin{array}{l}\text { Importância } \\
\text { e sentido de } \\
\text { oportunidade } \\
\text { do tempo: } \\
\text { - Nas preferên- } \\
\text { cias de compras; } \\
\text { - Nos processos } \\
\text { (produção, inova- } \\
\text { ção e gestão); } \\
\text { - Na estratégia; } \\
\text { - Na competição } \\
\text { em geral. }\end{array}$ & $\begin{array}{l}\text { Tempo relativo } \\
\text { dedicado às } \\
\text { atividades: } \\
\text { - Estratégicas; } \\
\text { - Opera- } \\
\text { cionais ou } \\
\text { correntes, } \\
\text { incluindo } \\
\text { as relacio- } \\
\text { nadas com } \\
\text { a estrutura } \\
\text { empresarial. }\end{array}$ \\
\hline $\begin{array}{l}\text { DIAGNÓS- } \\
\text { TICO: } \\
\text { com base nas } \\
\text { respostas às } \\
\text { seguintes } \\
\text { questões do } \\
\text { questionário } \\
\text { (Q18) }\end{array}$ & $\begin{array}{l}\text { DIAGNÓS- } \\
\text { TICO: } \\
\text { com base nas } \\
\text { respostas às } \\
\text { seguintes } \\
\text { questões do } \\
\text { questionário } \\
\text { (Q19) }\end{array}$ & $\begin{array}{l}\text { DIAGNÓs- } \\
\text { TICO: } \\
\text { com base nas } \\
\text { respostas às } \\
\text { seguintes } \\
\text { questões do } \\
\text { questionário } \\
\text { (Q8 e Q16) }\end{array}$ & $\begin{array}{l}\text { DIAGNÓS- } \\
\text { TICO: } \\
\text { com base nas } \\
\text { respostas às } \\
\text { seguintes } \\
\text { questões do } \\
\text { questionário } \\
\text { (Q17) }\end{array}$ & $\begin{array}{l}\text { DIAGNÓSTICO: } \\
\text { com base nas } \\
\text { respostas às se- } \\
\text { guintes questões do } \\
\text { questionário } \\
\text { (Q9 e Q10, Q13 a } \\
\text { Q15, Q22 a Q24, } \\
\text { Q37, Q39 e Q40) }\end{array}$ & $\begin{array}{l}\text { DIAGNÓSTICO: } \\
\text { com base nas } \\
\text { respostas às } \\
\text { seguintes questões } \\
\text { do questionário } \\
\text { (Q25 a Q28) }\end{array}$ & $\begin{array}{l}\text { DIAGNÓSTICO: } \\
\text { com base nas } \\
\text { respostas às se- } \\
\text { guintes questões } \\
\text { do questionário } \\
\text { (Q20) }\end{array}$ & $\begin{array}{l}\text { DIAGNÓS- } \\
\text { TICO: } \\
\text { com base nas } \\
\text { respostas às } \\
\text { seguintes } \\
\text { questôes do } \\
\text { questionário } \\
\text { (Q29) }\end{array}$ \\
\hline \multicolumn{8}{|c|}{ Matriz de Desenvolvimento Operacional Dinâmico (MADED) } \\
\hline \multicolumn{8}{|c|}{$\begin{array}{l}\text { PROPOSTAS DE MANOBRAS ESTRATÉGICAS } \\
\text { (Numa lógica SWOT Matrix, tendo em conta os referenciais do OE e o diagnóstico aos recursos empresariais e relações C-A-D da } \\
\text { GIRE-br) }\end{array}$} \\
\hline
\end{tabular}




\begin{tabular}{|l|}
\hline SO - Pontos Fortes Para Aproveitar Oportunidades \\
Proposta de Ação SO1: \\
Proposta de Ação SO2: \\
\hline$\ldots$ \\
\hline ST - Pontos Fortes Para Evitar Ameaças \\
\hline Proposta de Ação ST1: \\
Proposta de Ação ST2: \\
$\ldots .$. \\
\hline WO - Modificar Pontos Fracos Aproveitando Oportunidades \\
\hline Proposta de Ação WO1: \\
Proposta de Ação WO2: \\
$\ldots .$. \\
\hline WT - Minimizar Pontos Fracos e Evitar Ameaças \\
\hline Proposta de Ação WT1: \\
Proposta de Ação WT2 \\
\hline
\end{tabular}

Fonte: elaboração própria.

\section{RESULTADOS DO ESTUDO EMPÍRICO}

Os resultados do diagnóstico interno evidenciaram que das 125 vinícolas estudadas, 116 são empresas privadas e 9 são cooperativas (todas do RGS), relativamente jovens e que empregam muitos trabalhadores (3208), possuindo dirigentes experientes nos cargos de topo. $\mathrm{O}$ dirigente de topo, majoritariamente, tem formação acadêmica superior.

Em termos organizacionais existe um ambiente de maior informalidade nas empresas privadas do que nas cooperativas, acontecendo o mesmo em relação ao portfólio de marcas, ou seja, embora este esteja em declínio, é maior nas empresas privadas do que nas cooperativas. As preocupações com a inovação (também em queda), centram-se mais nos aspectos relacionados com o produto do que nos comerciais.

A maioria das vinícolas, apesar de ter vinha própria (e jovem), compra uva a terceiros. A vinha tem sido alvo de investimentos significativos nos últimos anos. Os vinhos indiferenciados predominam, mas estão em decadência, contrariamente aos vinhos finos, tranquilos e espumantes.

As expectativas dos dirigentes relativamente ao aumento das vendas, num futuro próximo, são prudentes. A internacionalização é débil, estando a maioria das estruturas comerciais das empresas 
viradas para o mercado interno. Constata-se uma indefinição estratégica latente entre diferenciação pela qualidade (vinhos finos) e competição por preços e custos (vinhos indiferenciados) - o "contra modelo brasileiro".

Os investimentos, materiais e imateriais são crescentes e relevantes, inclusive, na área comercial. Os resultados líquidos (médios) das empresas são positivos, mas a rentabilidade dos investimentos é decrescente.

Na maioria das vinícolas, os sistemas e tecnologias de informação estão mais focados na vertente contabilístico-financeira (gestão corrente) do que na vertente empresarial global (gestão estratégica).

Em termos de diagnóstico externo, ao nível da envolvente contextual (macroambiente), os resultados da aplicação do método PEST, evidenciam um contexto político-legal brasileiro turbulento, focado numa política de liberalização econômica, com o país bem inserido em blocos políticos internacionais (G20, Mercosul, Brics, Unasul...). O contexto econômico-social atual é difícil: o desemprego cresce, o rendimento das famílias deteriora-se, os impostos estão altos e o investimento é baixo. A boa notícia vem do lado da inflação: está controlada. Assiste-se, hoje, a sinais de saída de uma recessão severa (com epicentro em 2015 e 2016). Quanto ao contexto tecnológico-científico, importa referir que o investimento em P\&D é crescente, mas continua muito inferior (menos de metade) ao dos países ricos. A repartição de verbas de $P \& D$ está demasiado concentrada em alguns Estados (Sudeste e São Paulo). O registro de patentes está em ascenção, mas o processo de aprovação continua moroso.

No que diz respeito à envolvente transacional (variáveis microambientais - setor), importa referir que, pela aplicação do modelo das cinco forças de Porter, se concluiu pela complexidade e baixa atratividade da indústria vitivinícola do RGS e do VSF.

Quanto aos resultados (análises estatísticas multivariadas) da exploração estratégica das empresas, mais concretamente no que diz respeito à identificação dos arquétipos de abordagens estratégicas, respectivos perfis e desempenhos econômicos subjacentes, há a salientar o seguinte:

- Foram identificados três dos quatro arquétipos de abordagem, teoricamente possíveis, notadamente, o Adaptativo (AD, com 62 
vinícolas), o Empreendedor-P (EP, com 52 vinícolas) e o Planejamento Artesanal (PA, com 11 vinícolas); o arquétipo Planejamento Sofisticado não foi identificado nas empresas do RGS e do VSF;

- Os três arquétipos identificados têm perfis significativamente diferenciados em termos de "lógica do empresário" e de "extensão da empresa e qualidade";

- Existe, no entanto, um conjunto amplo de traços comuns aos 3 arquétipos (variáveis contextuais cujas médias não são significativamente diferentes entre os arquétipos de empresas) que são reveladores, possivelmente, de uma cultura enraizada e/ou de um contexto geral muito específico (crise): internacionalização incipiente, ambição estratégica muito prudente, organização focada no informal, produção majoritária de vinhos indiferenciados e minoritária de vinhos finos, sistemas e tecnologias de informação de natureza, essencialmente, contabilístico-financeira, com foco na gestão corrente, e crescente intensidade de capital;

- A esmagadora maioria das empresas tem processos estratégicos pouco formalizados ( $\mathrm{AD}$ e $\mathrm{EP}$ ), mas o maior desempenho econômico (vendas) é conseguido pelo arquétipo PA, precisamente o menos utilizado (só 11 empresas) e com um processo estratégico fortemente formalizado.

No âmbito da exploração da vertente estratégica das empresas, o diagnóstico foi ainda complementado com a análise de oito corredores estratégicos (Octógono Estratégico), cujas referências constituem a base para um conjunto de ações a propor, no intuito de melhorar a competitividade das vinícolas do RGS e do VSF. Esses corredores estratégicos são: postura estratégica da direção (CE1-PE), vias de crescimento (CE2-VC), níveis de ambição estratégica (CE3-NAE), hierarquia de objetivos (CE4-HO), lógicas estratégico-empresariais (CE5-LEE), internacionalização e dispersão global de atividades (CE6-IDGA), oportunidade e tempo (CE7-OT) e equlíbrio de gestão (CE8-EG). Os principais resultados da análise de cada um destes corredores estratégicos estão sintetizados abaixo: 


\section{Quadro sinóptico 1. Síntese do Octógono Estratégico}

\section{CORREDORES ESTRATÉGICOS DO OCTÓGONO}

\section{$\checkmark$ (CE1-PE) - Postura Estratégica:}

Posturas de Crescimento (expansão interna), de Desenvolvimento (inovações técnico-produtivas e comerciais) e de Manutenção (estratégias de nicho, com o vinho branco, e de especialização, com o vinho indiferenciado). Não foram identificadas posturas estratégicas de Sobrevivência (desinvestimento ou liquidação em curso).

\section{$\checkmark \quad$ (CE2-VC) - Vias de Crescimento:}

A via de crescimento orgânico é largamente majoritária.

\section{$\checkmark$ (CE3-NAE) - Níveis de Ambição Estratégica:}

Perfil de ambição estratégica prudente: (i) preferência por estratégias menos ambiciosas ( $37 \%$ das empresas preferem as estratégias de Penetração de Mercados) e intermediárias em ambição de crescimento (56\% preferem estratégias de Desenvolvimento de Produtos (19\%) ou de Desenvolvimento de Mercados (37\%); (ii) também menor ambição em termos de dinâmica inovadora total para crescer (só 7\% das empresas revelaram querer crescer, concomitantemente, através de novos mercados e de novos produtos). São projetadas vendas on-line para um futuro próximo ( 3 anos).

\section{$\checkmark \quad$ (CE4-HO) - Hierarquia de Objetivos:}

A maioria das empresas (mais de $80 \%$ ) foca-se na sua sustentabilidade (procura a prazo de maiores rentabilidades para os investimentos), em detrimento do imediatismo (procura da segurança imediata da liquidez).

\section{$\checkmark \quad$ (CE5-LEE) - Lógicas Estratégico-Empresariais:}

A carteira padrão de produtos é constituída por vinhos indiferenciados (produto majoritário), vinhos finos, e outros derivados da uva e do vinho, com foco no mercado interno. (a) Produtos-Mercados: A estratégia dominante é a de custos baixos (vinhos indiferenciados e/ou outros produtos derivados da uva e do vinho). (b) Integração Vertical: A integração a montante da produção requer mais atenção (pois há compra generalizada de uva a terceiros), embora os investimentos sejam crescentes e direcionados para aumentar a capacidade de produção de vinha própria. A integração a jusante da produção é fraca. No computo global, o recurso ao outsourcing é elevado. (c) Diversificação: É unicamente relacionada com a atividade base (vitivinicultura), não havendo diversificação não relacionada. (d) Internacionalização: Fraco nível de internacionalização, com poucas perspectivas de sofrer alterações substanciais num futuro mais ou menos próximo (o mercado interno continuará hegemônico). A modalidade de internacionalização preferida, hoje e no futuro, é a exportação, sendo o investimento direto, através de parcerias (joint-ventures ou outra), praticamente ausente das preferências/possibilidades.

$\checkmark$ (CE6-IDGA) - Internacionalização e Dispersão Global de Atividades ("bases domésticas"):

As vinícolas estão muito distantes, não só de uma dinâmica de internacionalização intensa, mas, principalmente, da competição de nível global: a configuração estratégico-estrutural das empresas não as capacita para mobilizar os recursos necessários para isso; a dimensão e a qualidade da procura são fracas; as empresas não têm condições de criar uma rede mundial de valor para competir globalmente. Só um fator é tido pelas empresas como favorável: a existência de matérias-primas e de outros inputs, em quantidade e qualidade, suficiente para competir no mercado global. 


\section{$\checkmark \quad$ (CE7-OT) - Oportunidade e Tempo:}

A grande maioria dos dirigentes (64\%) não atribui grande importância ao tempo, na tomada de decisão para aproveitar oportunidades e competir. Para os restantes dirigentes $(36 \%)$, o fator tempo é fundamental e, se for bem gerido, potenciará o sentido de oportunidade, principalmente, em assuntos de competitividade e estratégia.

\section{(CE8-EG) - Equilíbrio de Gestão:}

No global, constata-se algum descompasso entre estratégias, estruturas e operações. Existem 3 grupos de empresas: (a) Um primeiro grupo (próximo do arquétipo Empreendedor) com posturas estratégico-estruturais de "meio termo" (indefinição estratégica e/ ou competição em Custos na produção de vinhos finos) e, portanto, em "desequlíbrio de gestão"; (b) Um segundo grupo (mais próximo do arquétipo Adaptativo) também com posturas estratégico-estruturais de "meio termo" (competição em custos na produção de vinho indiferenciado, sem porte para isso; e competição em Diferenciação ou Enfoque nos vinhos finos, sem porte também suficiente) e, portanto, também em "desequlíbrio de gestão"; (c) Um terceiro grupo (mais próximo do arquétipo Planejamento Artesanal), com posturas estratégico-estruturais coerentes e em "equilíbrio de gestão", porém de rentabilidade baixa e market share em perda (especialização em vinhos indiferenciados).

Fonte: elaboração própria, com base nos resultados dos questionários.

No que diz respeito especificamente ao estudo de caso das empresas do VSF, os resultados sugerem que as suas dinâmicas de internacionalização não se afastam do padrão geral já detectado nas empresas brasileiras: um nível muito fraco de internacionalização, pois só duas empresas vendem para o mercado externo e numa proporção muito pequena da produção (5\%).

Os resultados também evidenciam que perante a pressão do fenômeno de globalização que se faz sentir no setor, as empresas respondem com estratégias muito diversas: Especialização (em vinhos indiferenciados), Enfoque (em vinhos finos, tranquilos e espumantes), Diferenciação (vinhos finos) e também de "Meio Termo" (estratégias indefinidas que articulam Especialização, Diferenciação e Diversificação). Cada uma das empresas segue uma ou várias destas estratégias.

As ações específicas para sustentar as estratégias delineadas são também muito diversas, passando pelo "ataque" aos mercados externos pela via da exportação, em consórcio ou com parceiro experiente nos mercados internacionais, ou ainda pela via de joint ventures. Quanto ao mercado interno, as ações concentram toda a sua energia em atividades de pesquisa, produção e promoção de produtos, incluindo a criação de marcas próprias (também de vinhos indiferenciados), com especial relevo para os vinhos espu- 
mantes, vinhos finos tranquilos e cachaça orgânica. De registrar que a pressão competitiva exercida sobre os espumantes nacionais é realativamente baixa, pois o mercado nacional está em expansão neste tipo de vinho. O mesmo não acontece com os outros produtos, notatamente os vinhos finos (forte pressão externa) e vinhos indiferenciados (grande pressão interna de competidores em volume).

As empresas sentem-se confortáveis com as suas estratégias, uma vez que só uma delas assumiu a necessidade de alterações específicas, reclamando apoio dos poderes públicos na competição "desigual" com os vinhos estrangeiros no próprio país, e também concentração acrescida na melhoria da "tipicidade" (terroir) como vetor de diferenciação acrescida.

Em termos de estruturas empresariais, também não se têm verificado mudanças significativas nos últimos tempos: só uma empresa revelou ter mudado a sua forma estrutural para uma holding (para gerir melhor os negócios nos mercados externos e interno). Para os dirigentes a estrutura deve seguir a estratégia e como esta não tem mudado, a primeira mantém-se inalterada.

Constata-se que todas as empresas assumem a existência de uma relação direta entre a abordagem estratégica seguida, o funcionamento operacional e o desempenho econômico. Na generalidade, os dirigentes empresariais estão satisfeitos com os desempenhos econômicos conseguidos.

Em suma, para além das condições naturais já conhecidas do VSF (terra disponível e mais barata que no RGS, clima propício e possibilidade de 2,5 safras anuais), os resultados das entrevistas e respectivos estudos de casos, não trouxeram grandes novidades relativamente às caraterísticas padrão da amostra total de empresas envolvidas no estudo. De salientar, talvez, uma caraterística merecedora de destaque: apesar do vinho indiferenciado ser majoritário também no VSF, a produção de vinhos finos (tranquilos e espumantes) é muito significativa na região.

Finalmente, tendo em conta todos os resultados que este estudo proporcionou, importa agora confrontá-los com as hipóteses operativas de investigação levantadas. Assim, pode-se deduzir o seguinte: 
- Hipótese Operativa 1 - "As dinâmicas do contexto de internacionalização do setor vitivinícola global induzem mais complexidade e variabilidade ao setor vitivinícola brasileiro e refletem níveis diferenciados de internacionalização".

Na sequência das análises qualitativas das envolventes contextual e transacional (método PEST, do modelo das Cinco Forças Competitivas) e também dos Estudos de Caso Múltiplos das vinícolas do VSF, constatamos evidências concretas de que, na decorrência de um contexto de internacionalização vitivinícola global dinâmico, a complexidade e a variabilidade do setor vitivinícola brasileiro não são de negligenciar: com efeito, o número de atores e de variáveis contextuais, assim como as respectivas relações e incerteza subjacentes ao regular funcionamento do setor, assim o sugerem. Por outro lado, os resultados quantitativos também permitiram constatar a existência de um incipiente e generalizado estágio de internacionalização das empresas brasileiras: esse é um dos traços comuns aos três arquétipos de abordagens estratégicas identificadas (análises estatísticas univariadas e multivariadas sobre as variáveis do contexto de internacionalização evidenciaram que as médias não são significativamente diferentes entre os arquétipos de empresas). O Octógono Estratégico (ver em Internacionalização e Dispersão Global de Atividades - "bases domésticas" - no Quadro sinóptico 1. Síntese do Octógono Estratégico, mais atrás) também identificou resultados semelhantes àqueles demonstrados abaixo.

Face ao exposto, será de concluir que não se rejeita, parcialmente, a Hipótese Operativa 1. Com efeito, se pelas evidências expostas, não será de rejeitar a primeira parte da Hipótese (as dinâmicas do contexto de internacionalização do setor vitivinícola global induzem mais complexidade e variabilidade ao setor vitivinícola brasileiro). Já quanto à segunda parte, ela deverá ser rejeitada, pois essas dinâmicas $\mathrm{NÃO}$ "refletem níveis diferenciados de internacionalização das empresas brasileiras". 
Tabela 2. Relação entre variáveis de contexto e tipos de abordagem estratégica: "Dinâmicas de Internacionalização"

\begin{tabular}{|c|c|c|c|c|}
\hline $\begin{array}{c}\text { TIPOS DE ABORDAGEM } \\
\text { VARIÁVEIS CONTINGENTES }\end{array}$ & $\begin{array}{l}\text { Média } \\
\text { Estatística } \\
\text { (p-value) }\end{array}$ & $\begin{array}{l}\text { Empreendedor (EP) } \\
\text { Média DP }\end{array}$ & $\begin{array}{l}\text { Adaptativo } \\
\text { (AD) } \\
\text { Média DP }\end{array}$ & $\begin{array}{l}\text { Planejamento } \\
\text { Artesanal (PA) } \\
\text { Média DP }\end{array}$ \\
\hline \multicolumn{5}{|c|}{ DINÂMICA DE INTERNACIONALIZAÇÃO } \\
\hline $\begin{array}{l}\text { - Domínio de idiomas (Q42 do } \\
\text { questionário) }\end{array}$ & $\begin{array}{c}10,30 \\
\left(0,517^{\mathrm{A}}\right)\end{array}$ & $11,17 \quad(7,498)$ & $\begin{array}{l}1,27 \\
(0,450)\end{array}$ & $\begin{array}{l}9,55 \\
(5,716)\end{array}$ \\
\hline $\begin{array}{l}\text { - № de países para onde a empresa } \\
\text { exporta (Q13) }\end{array}$ & $\begin{array}{c}0,46 \\
\left(0,867^{\mathrm{A}}\right) \\
\end{array}$ & $(0,995)$ & $\begin{array}{l}0,52 \\
(1,238) \\
\end{array}$ & $\begin{array}{l}0,45 \\
(0,934)\end{array}$ \\
\hline $\begin{array}{l}\text { - № de países de onde a empresa } \\
\text { importa (Q14) }\end{array}$ & $\begin{array}{c}0,06 \\
\left(0,302^{\mathrm{A}}\right)\end{array}$ & $(0,194)$ & $\begin{array}{l}0,10 \\
(0,298)\end{array}$ & $\begin{array}{l}0,00 \\
(0,000)\end{array}$ \\
\hline $\begin{array}{l}\text { - \% da exportação na venda total de } \\
\text { vinho (Q44.2) }\end{array}$ & $\begin{array}{c}8,45 \\
\left(0,824^{\mathrm{A}}\right)\end{array}$ & $7,67 \quad(22,308)$ & $\begin{array}{l}9,61 \\
(24,888)\end{array}$ & $\begin{array}{l}5,55 \\
(15,042)\end{array}$ \\
\hline $\begin{array}{l}\text { - \% da importação na compra total de } \\
\text { vinho (Q44.3) }\end{array}$ & $\begin{array}{c}7,20 \\
\left(0,197^{A}\right)\end{array}$ & $3,85 \quad(19,418)$ & $\begin{array}{l}11,29 \\
(31,906)\end{array}$ & $\begin{array}{l}0,00 \\
(0,000)\end{array}$ \\
\hline
\end{tabular}

Fonte: Elaboração própria, baseada nos outputs do SPSS.

Notas: *** Sig. <0,01; ** Sig. <0,05; *Sig. <0,1.

A-Estatística F de Snedcor: teste paramétrico Anova.

B-Estatistica Qui-quadrado: teste não paramétrico de independência.

- Hipótese Operativa 2 - "Coações ambientais internas provocam tipos de abordagem estratégica diferenciados e comportamentos contingentes de adaptação estratégica e estrutural". Em razão das evidências estatísticas constatadas: (a) nos testes efetuados (análises de variância simples - Anovas - ver as figuras de 6 a 9, após a Tabela 10), e multivariada - Manovas (ver figuras de 10 a 13), na sequência da aplicação da Análise Fatorial em Componentes Principais (ACP), Análise de Clusters - AC - ver a Figura 5, o Gráfico 1 e a Tabela 10 (todos mais adiante) e Análise Discriminante - AD - conforme Tabela 3 (logo abaixo), para confirmar os resultados da ACP - ver a Tabela 4, adiante - e da AC - às variáveis de contexto empresarial interno (ver tabelas 6 a 9 - todas mais adiante, que trazem a caracterização genérica dos tipos de abordagens estratégicas) e cuja síntese está plasmada no Quadro sinóptico 2 - logo após a Tabela 9 (adiante); (b) no diagnóstico complementar realizado no âmbito do Octógono 
Estratégico, com síntese no quadro sinóptico 1 (mais atrás);

(c) e no estudo de caso das empresas do VSF, referido no corpo do texto; não se rejeita a Hipótese Operativa 2.

Porém, será de salientar a existência de um conjunto de traços comuns (indiciadores de uma cultura enraizada e/ou de um contexto geral difícil), pois não se verifica evidência estatística em relação à diferença de médias para diversas variáveis contextuais internas.

Tabela 3. Resultados da classificação da Análise Discriminante

\begin{tabular}{l|c|c|c|c|c|c}
\hline \multirow{2}{*}{$\begin{array}{c}\text { Resultados da } \\
\text { Classificação }\end{array}$} & \multirow{2}{*}{ a,b,c } & Grupos & \multicolumn{3}{c|}{ Membros Englobados } & \multirow{2}{*}{ Total } \\
\cline { 3 - 6 } & & EP & AD & PA & & \\
\hline \multirow{3}{*}{ Original } & $\%$ & EP & $50(96,2 \%)$ & $02(3,8 \%)$ & & $52(100 \%)$ \\
\cline { 3 - 7 } & & AD & $11(17,7 \%)$ & $51(82,3 \%)$ & & $62(100 \%)$ \\
\cline { 3 - 7 } & PA & & & $11(100 \%)$ & $11(100 \%)$ \\
\hline \multirow{3}{*}{$\begin{array}{c}\text { Validação Cru- } \\
\text { zada }\end{array}$} & $\%$ & EP & $50(96,2 \%)$ & $02(3,8 \%)$ & & $52(100 \%)$ \\
\cline { 3 - 7 } & & AD & $11(17,7 \%)$ & $51(82,3 \%)$ & & $62(100 \%)$ \\
\cline { 3 - 7 } & & PA & & & $11(100 \%)$ & $11(100 \%)$ \\
\hline
\end{tabular}

Fonte: outputs A.D. (SPSS), (a) A validação cruzada classifica cada caso com as funções de classif. deduzidas de todos os casos, mas sem esse caso (b) 89,6\% dos casos foram classificados corretamente na função original. (c) $89,6 \%$ dos casos foram classificados corretamente na validação cruzada.

Tabela 4. Análise de Componentes Principais: os dois componentes extraídos

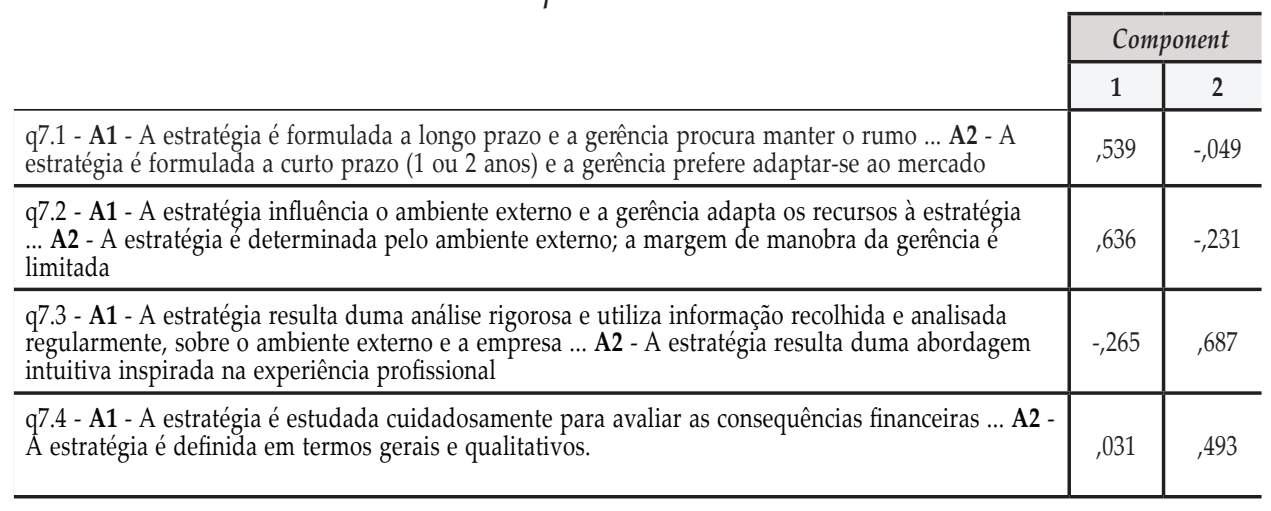

Fonte: elaboração própria, com base nos outputs do SPSS. 
Tabela 5. Identificação e composição dos fatores da ACP

\begin{tabular}{|c|c|}
\hline FATOR 1 (ANTECIPAÇÃO) & $\begin{array}{l}\text { Variância } \\
\text { Explicada }\end{array}$ \\
\hline $\begin{array}{l}\text { Q.7.1. A estratégia é formulada a longo prazo e a gerência procura manter } \\
\text { o rumo }\end{array}$ & \multirow{2}{*}{$40,33 \%$} \\
\hline $\begin{array}{l}\text { Q.7.2. A estratégia influencia o ambiente externo e a gerência adapta os } \\
\text { recursos à estratégia }\end{array}$ & \\
\hline FATOR 2 (FORMALIZAÇÃO) & \\
\hline $\begin{array}{l}\text { Q.7.3. A estratégia resulta duma análise rigorosa e utiliza informação } \\
\text { recolhida e analisada regularmente sobre o ambiente externo e a empresa. }\end{array}$ & \multirow{2}{*}{$40,54 \%$} \\
\hline $\begin{array}{l}\text { Q.7.4. A estratégia é estudada cuidadosamente para avaliar as consequên- } \\
\text { cias financeiras. }\end{array}$ & \\
\hline Total & $80,87 \%$ \\
\hline
\end{tabular}

Extraction Method: Principal Component Analysis. Rotation Method: Varimax with Kaiser Normalization.

a. Rotation converged in 3 iterations.

Fonte: Outputs do SPSS.

\section{Tabela 6. Relação entre variáveis de contexto e tipos de abordagem estratégica: "Lógica do Empresário"}

\begin{tabular}{|c|c|c|c|c|}
\hline $\begin{array}{c}\text { TIPOS DE ABORDAGEM } \\
\text { VARIÁVEIS CONTINGENTES }\end{array}$ & $\begin{array}{l}\text { Média } \\
\text { Estatística } \\
(p-v a l u e)\end{array}$ & $\begin{array}{c}\text { Empreendedor } \\
\text { (EP) }\end{array}$ & $\begin{array}{l}\text { Adaptativo } \\
\text { Média }\end{array}$ & $\begin{array}{r}\text { Planejamento } \\
\text { Artesanal (PA) } \\
\text { Média DP }\end{array}$ \\
\hline \multicolumn{5}{|l|}{ LÓGICA DO EMPRESÁRIO } \\
\hline $\begin{array}{l}\text { - Experiência: } \\
\text { - № de anos no cargo (Q6.2) }\end{array}$ & $\begin{array}{c}10,30 \\
\left(0,482^{\mathrm{A}}\right)\end{array}$ & $(7,498)$ & $1,27 \quad(0,450)$ & $9,55 \quad(5,716)$ \\
\hline $\begin{array}{l}\text { - Tipo de inovação: } \\
\text { - Produtiva ou comercial } \\
\text { (Q34) }\end{array}$ & $\begin{array}{c}1,29 \\
\left(0,137^{\mathrm{B}}\right)\end{array}$ & $\begin{array}{l}75 \% \\
\text { (Essencialmente } \\
\text { produtiva) }\end{array}$ & $\begin{array}{c}72,6 \% \\
\text { (Essencialmente } \\
\text { produtiva) }\end{array}$ & $\begin{array}{l}54,5 \% \\
\text { (Essencialmente } \\
\text { comercial) }\end{array}$ \\
\hline $\begin{array}{l}\text { - Dinâmica inovadora: № de } \\
\text { novos produtos nos últimos } \\
3 \text { anos }(\mathrm{Q} 35) \text { : } \\
\text { - } 2011\end{array}$ & $\begin{array}{c}0,78 \\
\left(0,265^{\mathrm{A}}\right)\end{array}$ & $(1,502)$ & $0,63 \quad(1,485)$ & $0,45 \quad(0,522)$ \\
\hline - $\quad 2012$ & $1,54\left(0,758^{\AA}\right)$ & $(2,798)$ & $(9,192)$ & $0,64 \quad(1,027)$ \\
\hline - $\quad 2013$ & $1,94\left(0,048^{\mathrm{A}}\right)$ & $(0,860)$ & $1,85 \quad(0,865)$ & $\begin{array}{c}2,55 \quad(0,688) \\
\mathrm{PA}>\mathrm{EP}^{*} \\
\mathrm{PA}>\mathrm{AD}^{*}\end{array}$ \\
\hline $\begin{array}{l}\text { - Postura técnico-produtiva: } \\
\text { - Média do \% do tempo de } \\
\text { trabalho dedicado à ativida- } \\
\text { de produtiva no último ano } \\
\text { (Q21) }\end{array}$ & $\left(0,126^{\mathrm{B}}\right)$ & $\begin{array}{l}32,7 \% \\
\text { (Postura técnico- } \\
\text {-produtiva ocupa } \\
\text { entre } 51 \text { a } 80 \%\end{array}$ & $\begin{array}{l}43,5 \% \\
\text { (Postura técni- } \\
\text { co-produtiva } \\
\text { ocupa entre } 21 \\
\text { a } 50 \%\end{array}$ & $\begin{array}{l}63,6 \% \\
\text { (Postura técnico- } \\
\text {-produtiva ocupa } \\
\text { entre } 51 \text { a } 80 \% \text { ) }\end{array}$ \\
\hline $\begin{array}{l}\text { - Ambição estratégica: } \\
\text { - Objetivo de evolução das } \\
\text { vendas em } 3 \text { anos (Q41) }\end{array}$ & $\left(0,616^{\mathrm{B}}\right)$ & $\begin{array}{c}50 \% \\
\text { (Pequeno au- } \\
\text { mento) }\end{array}$ & $\begin{array}{c}48,4 \% \\
\text { (Pequeno } \\
\text { aumento) }\end{array}$ & $\begin{array}{c}45,5 \% \\
\text { (Pequeno aumento) }\end{array}$ \\
\hline
\end{tabular}

Fonte: elaboração própria, baseada nos outputs do SPSS.

Notas: *** Sig. <0,01; ** Sig. <0,05; *Sig. <0,1.

A-Estatística F de Snedcor: teste paramétrico Anova.

B-Estatistica Qui-quadrado: teste não paramétrico de independência. 
Tabela 7. Relação entre variáveis de contexto e tipos de abordagem estratégica: "Caraterísticas da Atividade"

\begin{tabular}{|c|c|c|c|c|c|}
\hline $\begin{array}{c}\text { TIPOS DE ABORDAGEM } \\
\text { VARIÁVEIS CONTINGENTES }\end{array}$ & $\begin{array}{c}\text { Média } \\
\text { Estatística } \\
\text { (p-value) }\end{array}$ & $\begin{array}{l}\text { Empreendedor (EP) } \\
\text { Média } \quad \text { DP }\end{array}$ & $\begin{array}{c}\text { Adaptativo (AD) } \\
\text { Média } \quad \text { DP }\end{array}$ & \multicolumn{2}{|c|}{$\begin{array}{l}\text { Planejamento Artesanal } \\
\text { (PA) } \\
\text { Média }\end{array}$} \\
\hline \multicolumn{6}{|c|}{ CARATERÍSTICAS DA ATIVIDADE } \\
\hline \multicolumn{6}{|c|}{ Formalização organizacional: } \\
\hline $\begin{array}{l}\text { Organograma, autoridade, objetivos } \\
\text { (Q32) }\end{array}$ & $\left(0,260^{\mathrm{B}}\right)$ & $\begin{array}{c}69,2 \% \\
\text { (Implícita e informal) }\end{array}$ & $\begin{array}{c}62,9 \% \\
\text { (Implícita e } \\
\text { informal) }\end{array}$ & $\begin{array}{r}\text { (Implícita e } \\
\text { cita } \mathrm{e}\end{array}$ & $\begin{array}{l}5 \% \\
\text { formal/ Explí- } \\
\text { formal) }\end{array}$ \\
\hline \multicolumn{6}{|c|}{ Intensidade de capital - Imobilizado/vendas (Q47.1 e Q43.1): } \\
\hline 2011 & $\begin{array}{c}0,609 \\
\left(0,605^{\mathrm{A}}\right)\end{array}$ & $0,902 \quad(3,957)$ & $0,510 \quad(3,425)$ & $-0,217$ & $(0,927)$ \\
\hline 2012 & $\begin{array}{c}1,387 \\
\left(0,773^{\AA}\right)\end{array}$ & $1,161 \quad(3,867)$ & $1,827 \quad(9,138)$ & 0,216 & $(0,812)$ \\
\hline 2013 & $\begin{array}{c}2,211 \\
\left(0,588^{\AA}\right)\end{array}$ & $3,076 \quad(9,929)$ & $1,748 \quad(7,427)$ & 0,358 & $(0,907)$ \\
\hline
\end{tabular}

Fonte: Elaboração própria, baseada nos outputs do SPSS.

Notas: ${ }^{* *}$ Sig. $<0,01$; ${ }^{* *}$ Sig. $<0,05$; ${ }^{*}$ Sig. $<0,1$.

A-Estatística F de Snedcor: teste paramétrico Anova.

B-Estatistica Qui-quadrado: teste não paramétrico de independência.

Tabela 8. Relação entre variáveis de contexto e tipos de abordagem estratégica: "Extensão da Empresa e Qualidade"

\begin{tabular}{|c|c|c|c|c|}
\hline $\begin{array}{c}\text { TIPOS DE ABORDAGEM } \\
\text { VARIÁVEIS CONTINGENTES }\end{array}$ & $\begin{array}{c}\text { Média } \\
\text { Estatística } \\
\text { (p-value) }\end{array}$ & $\begin{array}{l}\text { Empreendedor (EP) } \\
\text { Média } \\
\text { DP }\end{array}$ & $\begin{array}{l}\text { Adaptativo (AD) } \\
\text { Média } \\
\text { DP }\end{array}$ & $\begin{array}{l}\text { Planejamento } \\
\text { Artesanal (PA) } \\
\text { Média DP }\end{array}$ \\
\hline \multicolumn{5}{|c|}{ EXTENSÃO DA EMPRESA E QUALIDADE } \\
\hline - Produção de vinho fino em 2013 (Q37.1.1) & $\begin{array}{c}78.723,60 \\
\left(0,455^{A}\right)\end{array}$ & $\begin{array}{c}128.492,54 \\
(554.038,451)\end{array}$ & $\begin{array}{c}42.138,72 \\
(145.934,173)\end{array}$ & $49.657,96 \quad(87,121,701)$ \\
\hline $\begin{array}{l}\text { Produção de vinho regional indif. } 2013 \\
\text { Q37.1.2) }\end{array}$ & $\begin{array}{c}136.658,20 \\
\left(0,191^{A}\right)\end{array}$ & $\begin{array}{c}104.113,41 \\
(250.587,719)\end{array}$ & $\begin{array}{c}139.642,79 \\
(256.955,273)\end{array}$ & $\begin{array}{c}273.684,11 \quad(480.161,269) \\
\text { PA }>E^{*}\end{array}$ \\
\hline - Produção de Outros em 2013 (Q37.1.3) & $\begin{array}{c}72.218,45 \\
\left(0,183^{A}\right)\end{array}$ & $\begin{array}{c}54.838,61 \\
(135.536,478)\end{array}$ & $\begin{array}{c}73.392,30 \\
(138.869,671)\end{array}$ & $\begin{array}{c}147.761,49 \quad(259.318,576) \\
\text { PA }>\mathrm{EP}^{*}\end{array}$ \\
\hline $\begin{array}{l}\text { \% de produção de vinho branco em } 2013 \\
\text { Q37.2.1) }\end{array}$ & $\begin{array}{l}23,803 \\
\left(0,172^{A}\right)\end{array}$ & $\begin{array}{c}28,141 \\
\mathrm{EP}>\mathrm{AD}^{*}\end{array}$ & $20,451 \quad(18,486)$ & $22,182 \quad(13,355)$ \\
\hline $\begin{array}{l}\text { \% de produção de vinho tinto em } 2013 \\
(Q 37.2 .2)\end{array}$ & $\begin{array}{l}69,153 \\
\left(0,265^{A}\right)\end{array}$ & $64,618(29,941)$ & $72,113(24,616)$ & $73,909(13,641)$ \\
\hline $\begin{array}{l}\text { \% de produção de vinho rosado em } 2013 \\
\text { Q37.2.3) }\end{array}$ & $\begin{array}{c}7,044 \\
\left(0,808^{A}\right)\end{array}$ & $7,240 \quad(16,094)$ & $7,435 \quad(18,434)$ & $3,909 \quad(5,356)$ \\
\hline Tamanho: № de empregados (Q3) & $\begin{array}{c}28,90 \\
\left(0,892^{\mathrm{A}}\right)\end{array}$ & $26,08 \quad(57,082)$ & $30,50 \quad(59,814)$ & $33,18 \quad(52,786)$ \\
\hline
\end{tabular}

Fonte: Elaboração própria, baseada nos outputs do SPSS.

Notas: *** Sig. <0,01; ** Sig. <0,05; ${ }^{*}$ Sig. $<0,1$.

A-Estatística F de Snedcor: teste paramétrico Anova. 
Tabela 9. Relação entre variáveis de contexto e tipos de abordagem estratégica: "Caraterísticas dos SI/TI"

\begin{tabular}{|c|c|c|c|c|}
\hline $\begin{array}{c}\text { TIPOS DE ABORDAGEM } \\
\text { VARIÁVEIS CONTINGENTES }\end{array}$ & $\begin{array}{l}\text { Média } \\
\text { Estatística } \\
\text { (p-value) }\end{array}$ & $\begin{array}{l}\text { Empreendedor (EP) } \\
\text { Média } \quad \text { DP }\end{array}$ & $\begin{array}{l}\text { Adaptativo (AD) } \\
\text { Média DP }\end{array}$ & $\begin{array}{l}\text { Planejamento Artesanal } \\
\begin{array}{l}\text { (PA) } \\
\text { Média } \quad \text { DP }\end{array}\end{array}$ \\
\hline \multicolumn{5}{|c|}{ CARATERÍSTICAS DOS SI/TI } \\
\hline $\begin{array}{l}\text { - Âmbito e sofisticação } \\
\text { - Tipo de aplicações informáticas } \\
\text { existentes (Q48) }\end{array}$ & $\left(0,603^{\mathrm{B}}\right)$ & $\begin{array}{l}\qquad 53,9 \% \\
\text { (Mais de acordo ou } \\
\text { totalmente de acordo } \\
\text { com } \mathbf{A}_{1} \text { : aplicações de } \\
\text { natureza contabi- } \\
\text { lístico-financeira: } \\
\text { faturamento, gestão } \\
\text { de stocks, gestão } \\
\text { orçamentária, análise } \\
\text { financeira) }\end{array}$ & $\begin{array}{l}\qquad 3,9 \% \\
\text { (Mais de acordo ou } \\
\text { totalmente de acordo } \\
\text { com } \mathbf{A}_{1:} \text { aplicações de } \\
\text { natureza contabilístico- } \\
\text {-financeira: faturamen- } \\
\text { to, gestão de stocks, } \\
\text { gestão orçamentária, } \\
\text { análise financeira) }\end{array}$ & $\begin{array}{l}\qquad 54,6 \% \\
\text { (Mais de acordo ou to- } \\
\text { talmente de acordo com } \\
\mathrm{A}_{1:} \text { aplicações de natureza } \\
\text { contabilístico-financeira: } \\
\text { faturamento, gestão de } \\
\text { stocks, gestão orçamentá- } \\
\text { ria, análise financeira) }\end{array}$ \\
\hline $\begin{array}{l}\text { - Integração } \\
\text { - Quantidade de ligações em rede } \\
\text { (Q49) }\end{array}$ & $\left(0,936^{\mathrm{B}}\right)$ & $\begin{array}{c}82,7 \% \\
\text { (Todos) }\end{array}$ & $\begin{array}{c}79,0 \% \\
\text { (Todos) }\end{array}$ & $\begin{array}{c}81,8 \% \\
\text { (Todos) }\end{array}$ \\
\hline
\end{tabular}

Fonte: Elaboração própria, baseada nos outputs do SPSS.

Notas: ${ }^{* * *}$ Sig. $<0,01 ;{ }^{* *}$ Sig. $<0,05 ;{ }^{*}$ Sig. $<0,1$.

A-Estatística F de Snedcor: teste paramétrico Anova.

B-Estatistica Qui-quadrado: teste não paramétrico de independência.

\section{Quadro sinóptico 2. Síntese: abordagens estratégicas, variáveis contextuais e desempenho}

\section{Tipos de Abordagens Estratégicas Identificados}

Só foram identificados 3 dos 4 tipos de abordagens estratégicas possíveis

Adaptativo (AD): 62 empresas - 50\% (formalização e antecipação fracas).

$>$ Empreendedor-P (EP): 52 empresas - 41\% (formalização fraca e antecipação forte).

$>$ Planejamento Artesanal: 11 empresas - 9\% (formalização forte e antecipação fraca).

$\checkmark$ O Planejamento Sofisticado (PS) é inexistente.

$\checkmark$ A esmagadora maioria (91\%) das empresas tem processos estratégicos pouco formalizados (AD e EP).

$\checkmark$ A maioria (59\%) das empresas tem processos estratégicos com fraco grau de antecipação (AD e PA).

$\checkmark$ Metade das empresas tem processos estratégicos pouco formalizados e com fraco grau de antecipação (AD).

\section{Perfis dos Tipos de Abordagens Estratégicas}

Diferenciados em algumas variáveis: "Lógica do Empresário" e "Extensão da Empresa e Qualidade" 


\section{ADAPTATIVO}

$\checkmark \quad$ Menor dinâmica de inovação;

$\checkmark$ Foco na vertente técnico-produtiva (mas dedica a esta menos de metade do seu tempo de trabalho diário);

$\checkmark$ Executivos com menos experiência (menor antiguidade no cargo);

$\checkmark$ Posição intermediária na produção de vinhos indiferenciados (e de outros derivados do vinho e da uva);

$\checkmark$ Menor produtor de vinhos finos;

$\checkmark \quad$ Menor produtor de vinhos brancos.

\section{EMPREENDEDOR}

Dinâmica de inovação intermediária (mas intensa);

$\checkmark$ Foco na vertente técnico-produtiva (dedicando-lhe mais de metade do seu tempo de trabalho diário);

$\checkmark$ Executivos experientes (com alguma antiguidade no cargo);

$\checkmark$ Menor produtor de vinhos indiferenciados (e de outros derivados do vinho e da vinha),

$\checkmark$ Maior produtor de vinhos finos;

$\checkmark \quad$ Maior produtor de vinhos brancos (estratégia de nicho).

\section{PLANEJAMENTO ARTESANAL}

$\checkmark$ Maior dinâmica de inovação;

$\checkmark$ Foco na vertente comercial (mas dedica a maior parte do seu trabalho diário a assuntos técnico-produtivos);

$\checkmark$ Executivos experientes (com alguma antiguidade no cargo);

$\checkmark$ Maior produtor de vinhos indiferenciados (e de outros derivados do vinho e da vinha),

$\checkmark$ Produção intermediária de vinhos finos;

$\checkmark$ Produção intermediária de vinhos brancos;

$\checkmark$ Empresas maiores e com mais empregados.

\section{Traços Comuns}

Reveladores de uma cultura regional ou nacional enraizada e/ou de um contexto geral muito específico (crise):

* Dinâmica de internacionalização incipiente (reduzido número de países de exportação e importação e estruturas comerciais com fraco domínio de idiomas estrangeiros);

* Dirigentes com ambição estratégica muito prudente;

* Organização empresarial focada na informalidade e no implícito;

* Crescente capitalização empresarial (intensidade de capital), mas empresas relativamente pequenas;

* Produção majoritária de vinhos indiferenciados e minoritária de vinhos finos;

* Produção majoritária (generalizada) de vinho tinto, minoritária de vinho branco e residual de vinho rosado;

* Sistemas e tecnologias de informação pouco sofisticados, essencialmente de natureza contabilístico-financeira, mas integrados (ligados em rede).

\section{Desempenho Econômico}

Aferido pelas Vendas, é maior no Planejamento Artesanal (precisamente o menos utilizado pelas empresas).

\section{Fonte: Elaboração própria.}


Figura 5. Dendrogram

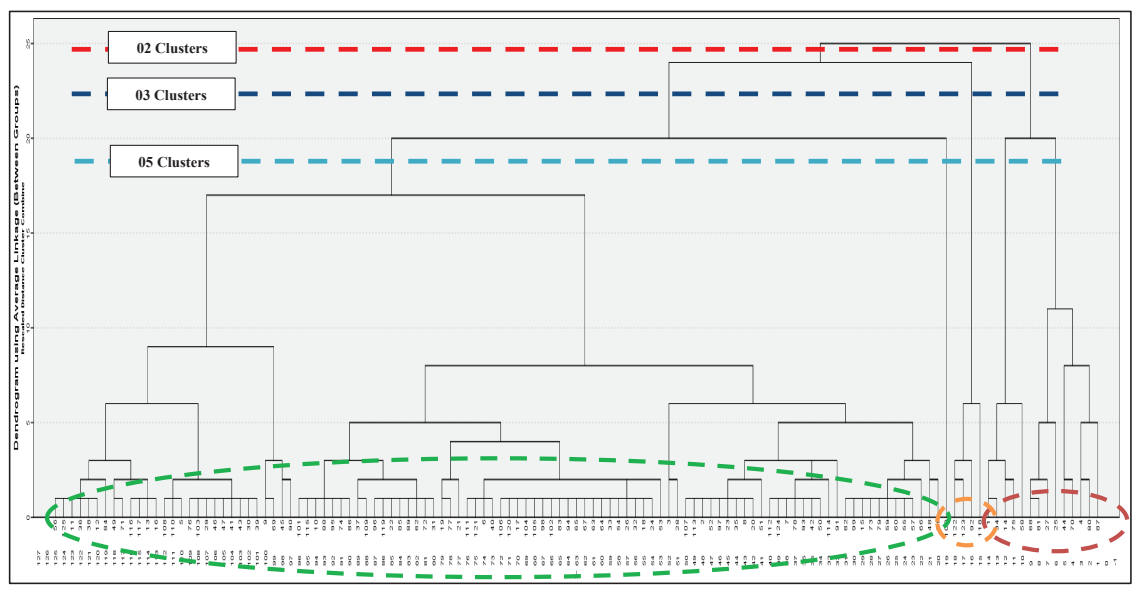

Fonte: Outputs do SPSS

Gráfico 1. Análise da distância entre Clusters

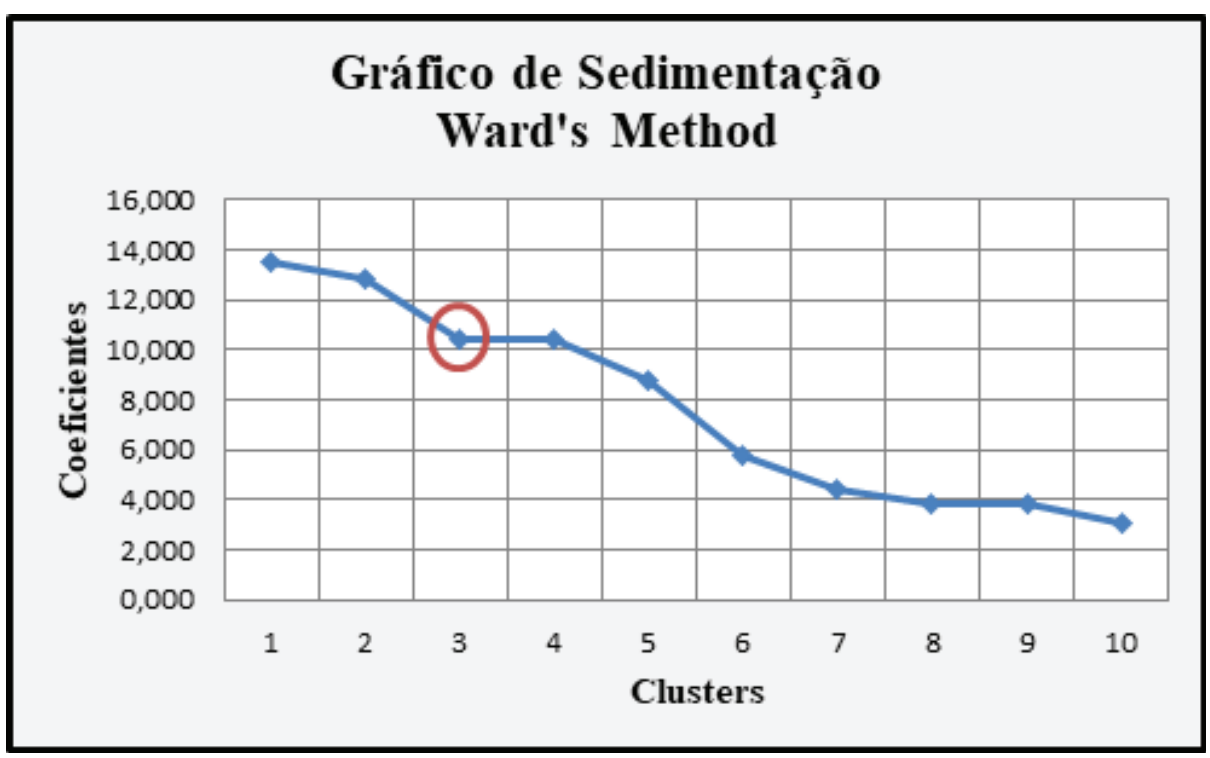

Fonte: Elaboração própria, baseada nos outputs do AC/SPSS. 
Tabela 10. Valores de $R^{2}$ para diferentes soluções do número de clusters

\begin{tabular}{c|c|c}
\hline No de Clusters & $\begin{array}{c}\mathbf{R}^{\mathbf{2}} \\
\text { (Ward Method) }\end{array}$ & Diferença \\
2 & 0,41246 & - \\
\hline 3 & 0,51372 & 0,10126 \\
\hline 5 & 0,64211 & 0,12839 \\
\hline
\end{tabular}

Fonte: Elaboração própria, baseada nos outputs do AC.

Figura 6. ANOVA - Teste aplicado às variáveis contextuais Extensão da Empresa e Qualidade

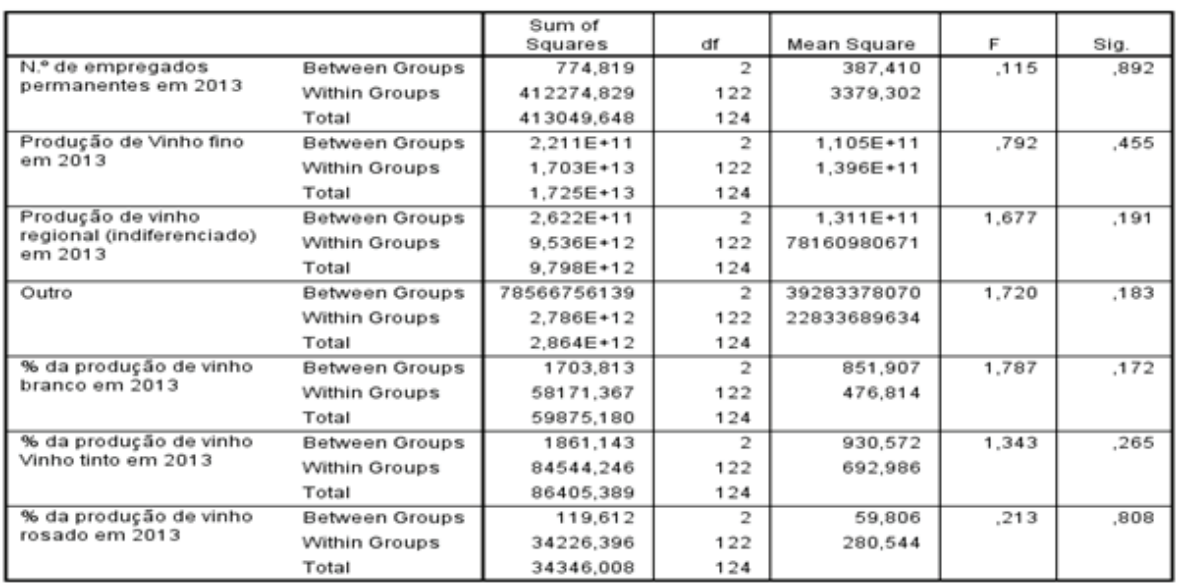

Fonte: Output do SPSS. 
ESTRATÉGIAS PARA O SETOR VITIVINÍCOLA BRASILEIRO, EM CONTEXTO GLOBAL:

desenvolvimentos de gestão no Rio Grande do Sul e no Vale do São Francisco

Figura 7. ANOVA - Teste aplicado às variáveis contextuais Lógica do Empresário

\begin{tabular}{|c|c|c|c|c|c|c|}
\hline & & $\begin{array}{l}\text { Sum of } \\
\text { Squares }\end{array}$ & df & Mean Square & $\mathrm{F}$ & Sig. \\
\hline \multirow[t]{3}{*}{ Antiguidade no cargo } & Between Groups & 68,701 & 2 & 34.351 & \multirow[t]{3}{*}{.735} & \multirow[t]{3}{*}{.482} \\
\hline & Within Groups & 5703,347 & 122 & 46,749 & & \\
\hline & Total & 5772,048 & 124 & & & \\
\hline \multirow{3}{*}{$\begin{array}{l}\text { Assuntos técnico- } \\
\text { produtivos }\end{array}$} & Between Groups & .856 & 2 & .428 & \multirow[t]{3}{*}{.499 } & \multirow[t]{3}{*}{.608} \\
\hline & Within Groups & 104,696 & 122 & .858 & & \\
\hline & Total & 105,552 & 124 & & & \\
\hline \multirow{3}{*}{$\begin{array}{l}\text { As inovaçסes relacionam- } \\
\text { se com }\end{array}$} & Between Groups & .816 & 2 & .408 & \multirow[t]{3}{*}{2,006} & \multirow[t]{3}{*}{.139} \\
\hline & Within Groups & 24,816 & 122 & .203 & & \\
\hline & Total & 25,632 & 124 & & & \\
\hline \multirow{3}{*}{$\begin{array}{l}\text { Produtos novos foram } \\
\text { introduzidos em } 2011\end{array}$} & Between Groups & 5,552 & 2 & 2.776 & \multirow[t]{3}{*}{1,343} & \multirow[t]{3}{*}{.265} \\
\hline & Within Groups & 252,176 & 122 & 2,067 & & \\
\hline & Total & 257,728 & 124 & & & \\
\hline \multirow{3}{*}{$\begin{array}{l}\text { Produtos novos foram } \\
\text { introduzidos em } 2012\end{array}$} & Between Groups & 25,296 & 2 & 12,648 & \multirow[t]{3}{*}{.277} & \multirow[t]{3}{*}{.758} \\
\hline & Within Groups & 5563,712 & 122 & 45,604 & & \\
\hline & Total & 5589,008 & 124 & & & \\
\hline \multirow{3}{*}{$\begin{array}{l}\text { Produtos novos foram } \\
\text { introduzidos em } 2013\end{array}$} & Between Groups & 4,495 & 2 & 2,247 & \multirow[t]{3}{*}{3,112} & \multirow[t]{3}{*}{.048} \\
\hline & Within Groups & 88,113 & 122 & .722 & & \\
\hline & Total & 92,608 & 124 & & & \\
\hline \multirow{3}{*}{$\begin{array}{l}\text { Objetivo realista para as } \\
\text { vendas da sua empresa. } \\
\text { nos próximos } 3 \text { anos }\end{array}$} & Between Groups & 2,325 & 2 & 1,162 & \multirow[t]{3}{*}{1,767} & \multirow[t]{3}{*}{.175} \\
\hline & Within Groups & 80,267 & 122 & .658 & & \\
\hline & Total & 82,592 & 124 & & & \\
\hline
\end{tabular}

Fonte: Output do SPSS.

Figura 8. ANOVA - Testes aplicado às variáveis contextuais Características da Atividade

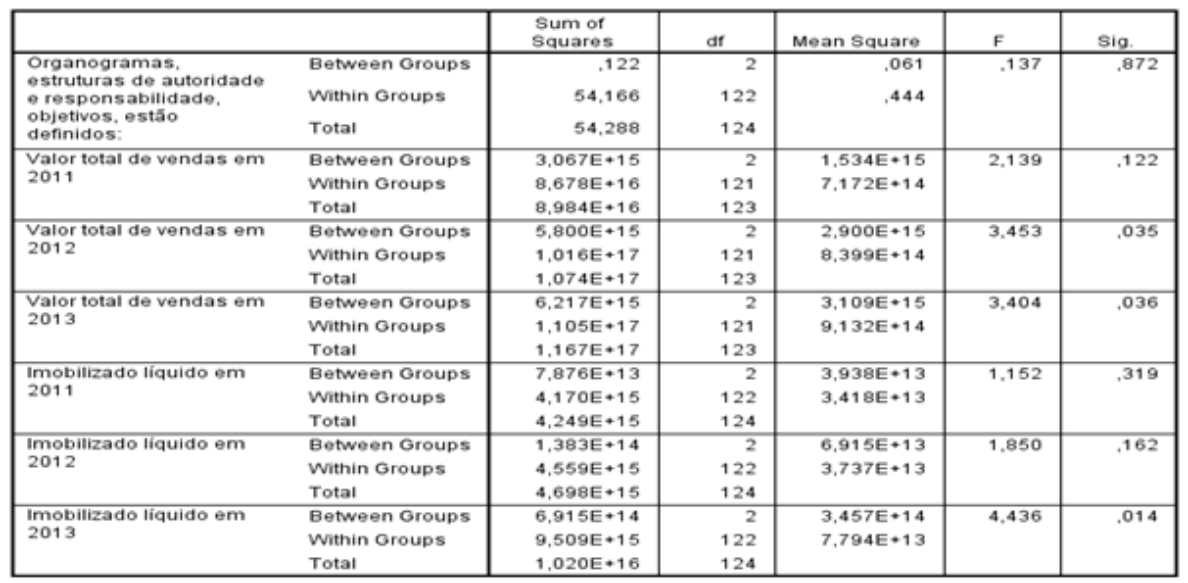

Fonte: Output do SPSS. 
Figura 9. ANOVA - Testes aplicado às variáveis contextuais Características dos Sistema da informação/Tecnologia da Informação

\begin{tabular}{|c|c|c|c|c|c|c|}
\hline & & $\begin{array}{l}\text { Sum of } \\
\text { Squares }\end{array}$ & df & Mean Square & $\mathrm{F}$ & Sig. \\
\hline $\begin{array}{l}\text { As aplicações } \\
\text { informáticas existentes } \\
\text { na empresa e que } \\
\text { considero mais } \\
\text { relevantes em termos do } \\
\text { SI/TI são... de natureza } \\
\text { contabilistico-financeira: } \\
\text { faturamento, gestão de } \\
\text { estoques, gestão } \\
\text { orçamentária, análise } \\
\text { financeira (A1)... As } \\
\text { aplicaçס̃es informáticas e }\end{array}$ & $\begin{array}{l}\text { Between Groups } \\
\text { Within Groups }\end{array}$ & 156,798 & 121 & .097 & .075 &, 928 \\
\hline $\begin{array}{l}\text { Os computadores da } \\
\text { empresa ligados em } \\
\text { rede são: }\end{array}$ & $\begin{array}{l}\text { Between Groups } \\
\text { Within Groups } \\
\text { Total }\end{array}$ & $\begin{array}{r}, 017 \\
42,271 \\
42,288\end{array}$ & $\begin{array}{r}2 \\
122 \\
124\end{array}$ & $\begin{array}{l}.009 \\
.346\end{array}$ & .025 & .975 \\
\hline
\end{tabular}

Fonte: Output do SPSS.

Figura 10. MANOVA (Teste de igualdade das matrizes de covariância ${ }^{a}$ ) - Teste aplicado às variáveis contextuais Extensão da Empresa e Qualidade

\begin{tabular}{|l|r|}
\hline Box's M & 142,646 \\
F & 22,652 \\
df1 & 6 \\
df2 & 5719,594 \\
Sig. &, 000 \\
\hline
\end{tabular}

Tests the null hypothesisthat the observed covariance matrices ofthe dependent variables are equal across groups. Design: Intercept + QCL_5 Fonte: Output do SPSS.

Figura 11. MANOVA (Teste de igualdade das matrizes de covariância ${ }^{a}$ ) - Teste aplicado às variáveis contextuais Lógica do Empresário

\begin{tabular}{|l|r|}
\hline Box's M & 158,203 \\
F & 2,319 \\
df1 & 56 \\
df2 & 2526,256 \\
Sig. &, 000 \\
\hline
\end{tabular}

Tests the null ypothesis that the observed covariance matrices of the dependent variables are equal across groups. a. Design: Intercept + QCL_5

Fonte: Output do SPSS. 
Figura 12. MANOVA (Teste de igualdade das matrizes de covariância ${ }^{a}$ )

- Teste aplicado às variáveis contextuais Características da Atividade

\begin{tabular}{|l|r|}
\hline Box's M & 873,501 \\
F & 12,498 \\
df1 & 56 \\
df2 & 1995,847 \\
Sig. & .000 \\
\hline
\end{tabular}

$$
\begin{aligned}
& \text { Tests the null } \\
& \text { hypothesis that the } \\
& \text { observed } \\
& \text { covariance matrices } \\
& \text { of the dependent } \\
& \text { variables are equal } \\
& \text { across groups. }
\end{aligned}
$$

a. Design:

\begin{tabular}{|c|c|}
\hline Box's M & 1,743 \\
\hline$F$ & .277 \\
\hline df1 & 6 \\
\hline df2 & 5736,883 \\
\hline Sig. & .948 \\
\hline \multicolumn{2}{|c|}{$\begin{array}{l}\text { Tests the null } \\
\text { hypothesis that the } \\
\text { observed } \\
\text { covariance matrices } \\
\text { of the dependent } \\
\text { variables are equal } \\
\text { across groups. }\end{array}$} \\
\hline
\end{tabular}

Intercept + QCL_5

Fonte: Output SPSS.

Figura 13. MANOVA (Teste de igualdade das matrizes de covariância ${ }^{a}$ ) - Teste aplicado às variáveis contextuais Sistema da informação/Tecnologia da Informação
a. Design:
Intercept + QCL_5

Fonte: Output do SPSS

- Hipótese Operativa 3 - "Existe relação entre os tipos de abordagem estratégica e o desempenho econômico das empresas". 
Igualmente não se rejeita, a Hipótese Operativa 3, em face das conclusões retiradas da Tabela 11 (abaixo), na sequência de testes estatísticos realizados, entre os quais a Anova e Descritivas (conforme as figuras 14 e 15, adiante) aos indicadores ROI (retorno do investimento) e Valor Médio das Vendas Totais (este foi o indicador diferenciador), para os diversos tipos de abordagens estratégicas (ver Tabela 11, abaixo).

Tabela 11. Relação entre os tipos de abordagem estratégica e o desempenho econômico

\begin{tabular}{|c|c|c|c|c|}
\hline \multirow[t]{2}{*}{$\begin{array}{l}\text { TIPOS DE ABORDAGEM } \\
\text { VARIÁVEIS CONTINGENTES }\end{array}$} & \multirow{2}{*}{$\begin{array}{l}\text { Média } \\
\text { Estatística } \\
\text { ( } p \text {-value) }\end{array}$} & Empreendedor (EP) & Adaptativo (AD) & \multirow{2}{*}{$\begin{array}{l}\text { Planejamento } \\
\text { Artesanal } \\
\text { (PA) } \\
\text { Média DP }\end{array}$} \\
\hline & & Média DP & Média DP & \\
\hline \multicolumn{5}{|c|}{ DESEMPENHO ECONÔMICO } \\
\hline $\begin{array}{l}\text { Rentabilidade econômica (Return On } \\
\text { Investment ROI): Resultado líquido/ } \\
\text { Imobilizado líquido (média 2011/2013) } \\
\text { (Q47.1 e Q47.2) }\end{array}$ & $\begin{array}{c}0,6818 \\
\left(0,331^{A}\right)\end{array}$ & $1,0891 \quad(2,26467)$ & $0,3341 \quad(0,60161)$ & $0,1153 \quad(0,02550)$ \\
\hline $\begin{array}{l}\text { Valor médio das vendas totais ( } 2011 \\
-2013) \\
(Q 43.1)\end{array}$ & $\begin{array}{c}\mathrm{R} \$ 5.980 .246 \\
\left(0,053^{\mathrm{A}}\right)\end{array}$ & $\begin{array}{l}\mathrm{R} \$ 1.611 .260 \\
(\mathrm{R} \$ 4.985 .859)\end{array}$ & $\begin{array}{c}\mathrm{R} \$ \text { 6.462.096 } \\
(\mathrm{R} \$ 33.394 .624)\end{array}$ & $\begin{array}{c}\mathrm{R} \$ 25.711 .500 \\
(\mathrm{R} \$ 56.814 .860) \\
\mathrm{PA}>\mathrm{EP}^{* *} \\
\mathrm{PA}>\mathrm{AD}^{* *}\end{array}$ \\
\hline
\end{tabular}

Fonte: Elaboração própria, baseada nos outputs do SPSS.

Notas: *** Sig. $<0,01 ;{ }^{* *}$ Sig. $<0,05 ;{ }^{*}$ Sig. $<0,1$.

A-Estatística F de Snedcor: teste paramétrico Anova.

B-Estatistica Qui-quadrado: teste não paramétrico de independência.

Figura 14. ANOVA (Dependent Variable: volume médio das vendas totais; Rentabilidade econômica)

\begin{tabular}{|ll|r|r|r|r|r|}
\hline & & \multicolumn{1}{c|}{$\begin{array}{c}\text { Sum of } \\
\text { Squares }\end{array}$} & \multicolumn{1}{c|}{ df } & Mean Square & \multicolumn{1}{c|}{ F } & Sig. \\
\hline Volume_Médio_Negócio & Between Groups & $4,900 \mathrm{E}+15$ & 2 & $2,450 \mathrm{E}+15$ & 3,014 &, 053 \\
& Within Groups & $9,835 \mathrm{E}+16$ & 121 & $8,128 \mathrm{E}+14$ & & \\
& Total & $1,032 \mathrm{E}+17$ & 123 & & & \\
\hline Valor_Médio_ROI & Between Groups & 6,090 & 2 & 3,045 & 1,140 &, 331 \\
& Within Groups & 98,833 & 37 & 2,671 & & \\
& Total & 104,923 & 39 & & & \\
\hline
\end{tabular}

Fonte: Output do SPSS. 
Figura 15. Descritivas (Dependent Variable: volume médio das vendas totais; Rentabilidade econômica)

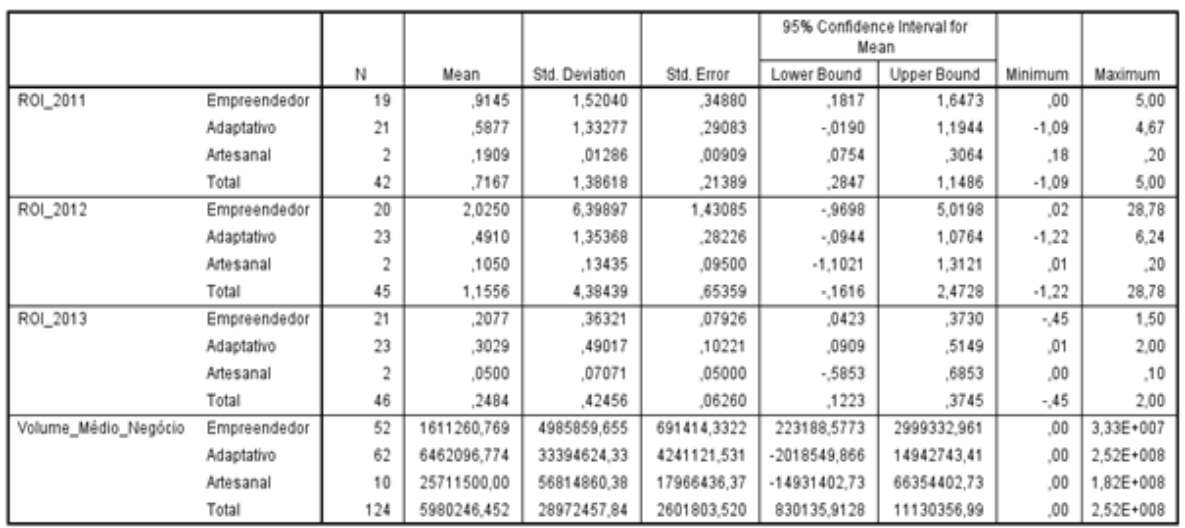

Fonte: Output do SPSS.

Em suma, pode-se afirmar que as dinâmicas do contexto de internacionalização do setor vitivinícola global induzem mais complexidade e variabilidade ao setor vitivinícola brasileiro e que coações ambientais internas provocam tipos de abordagens estratégicas diferenciados e comportamentos contingentes de adaptação estratégica e estrutural. E, existindo relação entre esses tipos de abordagens estratégicas e o desempenho econômico das empresas, há abordagens estratégicas que têm maiores desempenhos que outras.

\section{CONSIDERAÇÃOES FINAIS}

Esse estudo teve como objetivo geral oferecer um diagnóstico da competitividade empresarial das vitivinícolas do Rio Grande do Sul e do Vale do Submédio do São Francisco, no Brasil, por meio da identificação dos tipos de abordagens estratégicas estabelecidos e respectivos impactos nas suas performances econômicas, para, no final, propor linhas adicionais de ação estratégica (para o setor e para as empresas) que sejam capazes de melhorar as hipóteses de sucesso no ambiente global. Para uma melhor operacionalização do trabalho, este objetivo geral foi desagregado em quatro objetivos específicos: (1) Identificar as estruturas existentes e as estratégias em curso nas empresas do RGS e do polo emergente do VSF; (2) Identificar e discutir os tipos de abordagem estratégica que norteiam 
as decisões nessas empresas; (3) Identificar os impactos ambientais internos e externos nos desempenhos econômicos das empresas; (4) Formular propostas estratégicas renovadas para uma maior competitividade empresarial.

Para alcançar estes objetivos específicos, foi traçado um quadro metodológico devidamente fundamentado e adaptado ao objeto de estudo, de modo a submeter a teoria à prova dos fatos, mas salvaguardando as possibilidades de refutação. O referencial de operacionalização metodológica foi a Grelha Integrada de Reflexão Estratégica (GIRE), inicialmente desenvolvida por Sousa (2000), com inspiração nos trabalhos de Calori et al. (1997), e depois utilizada também por VIVAS (2012), por meio de uma variante designada de GIRE(i), que consistiu na sua aplicação a contextos de internacionalização de empresas vitivinícolas de Portugal. Posteriormente, a lógica da GIRE foi aplicada também por Ramos (2015), consubstanciando uma outra versão adaptada, agora a contextos de inovação estratégica de empresas do Rio Grande do Sul, tomando o nome de GIRE(inov), e, ainda, GIRE- $b r$, de gestão corporativa (RAMALHO, 2019).

Os resultados a que chegamos sugerem algumas conclusões a reter, permitindo-nos deduzir sobre a concretização dos objetivos específicos delineados para este trabalho.

Assim, num primeiro momento, o diagnóstico interno realizado (caraterísticas dos recursos e organização estrutural das empresas), permite concluir que a maioria das empresas é jovem, possuem dirigentes experientes e com formação acadêmica superior. Mas, apesar de possuírem vinhas próprias (igualmente jovens), compram uma quantidade importante de uvas a terceiros, a despeito dos investimentos na integração vertical a montante. Os vinhos indiferenciados são dominantes, embora em declínio, ao contrário dos vinhos finos, tranquilos e espumantes, e suco de uva, em ascensão. Do ponto de vista da estrutura organizacional (organograma, estruturas de autoridade e de responsabilidade nas empresas, definição dos seus objetivos), verificou-se uma tendência para a informalidade, com esta a ser maior nas empresas privadas em relação às cooperativas. O mesmo ocorre com o mix de produtos a comercializar: é maior nas empresas privadas do que nas cooperativas, muito embora em declíneo. Em termos comerciais verifica-se ainda que, majoritaria- 
mente, as vinícolas estão mais voltadas para o mercado interno e os seus dirigentes têm uma perspectiva conservadora das vendas para os próximos anos. A dificuldade de internacionalização é agravada pelo baixo desempenho da estrutura comercial no domínio de idiomas. Relativamente à inovação, igualmente em queda, ela está mais centrada nos aspectos produtivos do que nos comerciais. No que diz respeito à vertente financeira e de investimento, conclui-se que existe uma evolução satisfatória dos resultados líquidos das empresas (o que reforça a discussão em torno do "contra modelo brasileiro") mas, no entanto, as rentabilidades dos investimentos (resultado líquido/imobilizado líquido) são decrescentes. Quanto aos recursos de informação e respectivas tecnologias, estes são essencialmente de natureza contabilístico-financeira e, portanto, focados mais na gestão corrente do que na gestão estratégica.

Num segundo momento, foi feita a exploração da vertente estratégica das empresas, através da abordagem C-A-D, que coloca em relação os contextos (C), com os tipos de abordagem (A) estratégica desenvolvidos pelas empresas, e com os desempenhos (D) econômicos conseguidos.

No que diz respeito aos contextos (C), para identificar as variáveis macroambientais mais importantes (envolvente contextual), foi utilizado o método PEST, o que permitiu concluir pela existência de um contexto político-legal turbulento, em dificuldade e na direção da liberalização econômica, de um contexto econômico-social em recuperação lenta mas com a inflação sob controle, e de um contexto tecnológico-científico alvo de investimentos acrescidos em P\&D, mas concentrados na região sudeste e ainda longe de atingir os patamares dos países mais desenvolvidos. Quanto às variáveis microambientais (envolvente transacional), a sua identificação foi feita recorrendo ao modelo das cinco forças competitivas, aplicado ao setor vitivinícola de cada uma das regiões em estudo (RGS e VSF), o que permitiu concluir que existe um contexto complexo e de atratividade setorial relativamente baixa nas duas regiões estudadas.

Quanto aos tipos de abordagem (A) estratégica utilizados, as análises estatísticas multivariadas permitiram identificar três dos quatro arquétipos empresariais possíveis: o Adaptativo (AD, com 62 vinícolas), o Empreendedor-P (EP, com 52 vinícolas) e o Plane- 
jamento Artesanal (PA, com 11 vinícolas); não tendo sido identificado o arquétipo Planejamento Sofisticado. Sinteticamente, pode-se apontar que os três arquétipos identificados têm abordagens e perfis estatisticamente diferenciados nas dimensões "lógica do empresário" e "extensão da empresa e qualidade". Por outro lado, apresentam como traços identitários comuns terem baixos níveis de internacionalização, ambição estratégica conservadora em termos comerciais, informalidade organizacional acentuada, produção de vinhos indiferenciados maioritária, tecnologias de informação focadas na obtenção de elementos contabilístico-financeiros (o que revela uma ênfase de gestão mais voltada para as operações, em detrimento da estratégia) e crescente intensidade de capital (imobilizado/vendas). De registrar também a conclusão pela existência, na esmagadora maioria das empresas (114), de processos estratégicos pouco formalizados (arquétipos Adaptativo e Empreendedor).

Relativamente ao desempenho econômico (D), conclui-se que o maior desempenho é alcançado pelo arquétipo menos utilizado: o Planejamento Artesanal; porém constituído pelas empresas de maior porte.

Ainda no âmbito da exploração da vertente estratégica das empresas, o terceiro momento incidiu sobre oito corredores estratégicos de decisão que servem de base a propostas de ação estratégica para melhorar a competitividade das vinícolas. Esses corredores estratégicos são enquadrados e discutidos no âmbito de um instrumento de análise contruído também especificamente para este trabalho: o Octógono Estratégico. Os oito corredores estratégicos são os seguintes: (i) postura estratégica (direção); (ii) vias de crescimento; (iii) níveis de ambição estratégica; (iv) hierarquia de objetivos; (v) lógicas estratégico-empresariais; (vi) internacionalização e dispersão global de atividades (bases domésticas); (vii) oportunidades e tempo; (viii) equilíbrio de gestão.

O Octógono possibilitou igualmente a identificação de três grupos de empresas, concluindo-se que eles apresentam caraterísticas estratégicas diferenciadas.

O primeiro grupo, cujas caraterísticas são muito próximas daquelas que resultaram na formação do cluster Empreendedor-P, de perfil com forte antecipação e relativamente fraca formalização, é 
predominantemente enquadrado no "Meio Termo", porque as suas vinícolas padecem da falta de uma cultura competitiva bem delineada, pois tentam competir em custo na produção de vinhos finos.

O segundo grupo de vinícolas, majoritariamente, tenta competir em custo, produzindo vinhos indiferenciados, e também em diferenciação e enfoque, na produção de vinhos finos. É um grupo que acaba por resvalar igualmente para o "Meio Termo" (empresas de porte relativamente pequeno que querem tudo ao mesmo tempo) e tem caraterísticas próximas do cluster Adaptativo, de perfil estratégico com graus de antecipação e de formalização fracos, visando, portanto, um horizonte temporal curto e fazendo basear a definição e implementação da estratégia exclusivamente na experiência e intuição, numa perspetiva de reação adaptativa à envolvente.

O terceiro grupo de empresas compete em custo produzindo, majoritariamente, vinhos indiferencidos. Este grupo é formado pelas maiores empresas do setor vitivinícola. As suas caraterísticas são muito próximas do cluster de Planejamento Artesanal, apresentando um perfil estratégico com graus de formalização forte e de antecipação fraca. Isso significa que essas empresas estabelecem um processo estratégico um pouco mais elaborado em termos de planejamento, não padecendo, portanto, de inconsistências na resolução do "equilíbrio de prioridades", ao contrário dos dois grupos anteriores.

Finalmente, o quarto momento, explorou-se e discutiu-se as cinco empresas existentes no VSF, por meio do método de estudo de caso múltiplo. No final, o estudo de caso permitiu concluir que existe uma similaridade de abordagem estratégica com a maioria das empresas do RGS. E, quando confrontadas com pressões, aos níveis nacional ou global, apesar de pouco internacionalizadas, as empresas do VSF respondem com posicionamentos estratégicos diversificados (abrangendo vinhos correntes e vinhos finos), revelando um comportamento típico também do "Meio Termo", pois insistem na diferenciação pela qualidade (vinhos finos) concomitantemente à competição por preços e custos (vinhos indiferenciados) - refletindo assim o "contra modelo" brasileiro.

Do ponto de vista do design organizacional, as empresas do VSF não apresentam mudanças significativas nos tempos mais recentes, exibindo estruturas organizacionais do tipo linear (mecanicistas), 
centralizadas, com tendências rotineiras (taylorismo) e rigidez autocrática (escola burocrática), revelando dificuldades para responder com rapidez às exigências adaptativas-contingenciais do atual mundo dos negócios, incluindo inovações tecnológicas, de produtos e de processos.

Do ponto de vista do desempenho econômico, concluiu-se que a maioria das empresas demonstrou satisfação com os resultados.

Destaque-se que, a despeito do vinho corrente ser majoritário, o VSF já alcançou resultados importantes na produção de vinhos finos, tranquilos e espumantes, tanto do ponto de vista regional, quanto nacional (16\% de market share). Um dos grandes desafios presentes é encontrar uma tipicidade marcante para os seus vinhos, de maneira a delimitar um espaço competitivo próprio em níveis nacional e global.

Ao final, foram feitas propostas estratégicas de ação, para as vinícolas do RGS e do VSF e, consequentemente, para a vitivinicultura brasileira, seguindo a lógica SWOT MATRIX.

Pelo exposto, é nossa convicção que o trabalho atingiu os objetivos específicos estabelecidos, porquanto: (1) identificou as estruturas existentes e as estratégias em curso nas empresas do RGS e do VSF; (2) identificou e discutiu os tipos de abordagens estratégicas que norteiam as decisões nessas empresas; (3) identificou os impactos ambientais internos e externos nos desempenhos econômicos das empresas e, finalmente, foi possível (4) formular propostas estratégicas renovadas para uma maior competitividade empresarial. Em suma, foi possível arquitetar novas linhas estratégicas de ação para as vinícolas do RGS e do VSF, capazes de potencializarem a competitividade destas. Lembramos que isto constituiu o cerne da problemática deste estudo, cujas motivações encontraram a sua justificativa precisamente nos referenciais estratégicos que se poderiam acrescentar às instituições e empresas vitivinícolas, em termos de renovação de posicionamento competitivo (aos níveis nacional e mundial), e também no contributo acrescido que daí poderá advir para o desenvolvimento prático, nas regiões em referência, de um setor de atividade econômica importante; para além, naturalmente, do aprofundamento, sempre pertinente, das relações Universidade-Empresa (transferência de tecnologia). Pensamos ter conseguido tudo isto. 
Relativamente às hipóteses operativas de partida do trabalho, e após utilização da metodologia já aqui elencada, podemos concluir que as três foram confirmadas, sendo que a Hipótese Operativa 1, pelas evidências expostas, não será de rejeitar na sua primeira parte (as dinâmicas do contexto de internacionalização do setor vitivinícola global induzem mais complexidade e variabilidade ao setor vitivinícola brasileiro), já que quanto à segunda parte, ela deverá ser rejeitada, pois essas dinâmicas NÃO "refletem níveis diferenciados de internacionalização das empresas brasileiras".

Quanto à Hipótese Operativa 2 - "Coações ambientais internas provocam tipos de abordagem estratégica diferenciados e comportamentos contingentes de adaptação estratégica e estrutural", em razão das evidências estatísticas constatadas, ela não se rejeita.

No que diz respeito à Hipótese Operativa 3 - "Existe relação entre os tipos de abordagem estratégica e o desempenho econômico das empresas", ela igualmente não se rejeita na sequência dos testes estatísticos realizados ao Valor Médio das Vendas Totais (este foi o indicador diferenciador) para os diversos tipos de abordagens estratégicas.

Em conclusão, o estudo respondeu cabalmente aos diversos objetivos a que se propôs, assim como testou as hipóteses operativas levantadas. Permitiu ainda identificar um conjunto significativo de desafios que importa suplantar, dos quais destacamos seis:

- Os perfis de abordagens estratégicas estão claramente diferenciados nas empresas, mas existe um conjunto de traços comuns restritivos (internacionalização incipiente, ambição estratégica muito conservadora, empresas relativamente pequenas, excessiva informalidade organizacional e tecnologias de informação e comunicação pouco sofisticadas e, essencialmente, de natureza contabilístico-financeira) que são indiciadores de uma cultura enraizada e/ou de uma inércia negativista perante um contexto de crise que, sendo real, importa suplantar com rapidez, atuando sobre esses traços restritivos;

- Um "contra modelo brasileiro", focado nos vinhos indiferenciados que, apesar de ser sustentável no curto prazo, levanta muitas dúvidas e perigos a médio prazo; 
- Fraca atratividade do setor vitivinícola do RGS e do VSF, mas de elevado potencial e que é possível de melhorar;

- Um polo vitivinícola emergente (VSF) que é considerado a "nova latitude da vitivinicultura mundial", pelas vantagens comparativas que evidencia, mas que ainda não conseguiu transformar em vantagens competitivas;

- Indefinição estratégica evidente na maioria das empresas (Meio Termo);

- A esmagadora maioria das empresas tem processos estratégicos pouco formalizados (arquétipos Adaptativo e Empreendedor-P).

Convém ainda destacar que a generalização dos resultados do estudo para o universo de empresas fica assegurada, seja no que diz respeito ao segmento de empresas do Rio Grande do Sul pela garantia de generalização estatística, seja para as empresas do VSF, onde são estudadas todas as empresas existentes, salvaguardando-se ainda a possibilidade de se poder recorrer à designada generalização analítica de Yin (2010), ao defender que o método do estudo de caso salvaguarda sempre a possibilidade de confrontação dos resultados alcançados nos casos estudados, com os de outros casos semelhantes e/ou de outros estudos empíricos da mesma natureza já realizados e ainda com a teoria estabelecida (MINTZBERG, 1982).

As propostas de ação estratégica pretendem suplantar todos os desafios identificados. Da sua eficácia no terreno dependerá a robustez dos alicerces de desenvolvimento do setor vitivinícola brasileiro e, consequentemente, a sua competitividade futura. $\mathrm{O}$ sucesso dependerá de um espírito empresarial e institucional mais dinâmico no domínio vitivinícola e de um profissionalismo acrescido em toda a cadeia de valor. O empreendimento é enorme, devendo, por isso, envolver todos os agentes do setor: empresas, organismos profissionais e poderes públicos, aos seus mais diversos níveis. Naturalmente, tudo isto dependerá, em última análise, da capacidade de organização e da qualidade das pessoas envolvidas. São elas que, normalmente, fazem a diferença nestes processos de transformação.

A partir dos resultados desse conjunto de análises, são apontadas, logo a seguir, as propostas, visando uma competitividade 
acrescida, para cada grupo de vinícolas investigados no Brasil. De salientar que as bases conceptual e operacional para as propostas têm origem no Octógono Estratégico e na Matriz de Desenvolvimento Empresarial Dinâmico (MADED), criados especialmente para essa investigação (abrigando as lógicas das manobras estratégicas da SWOT MATRIX).

- Primeiro Grupo de Vinícolas (enquadrado no "Meio Termo" Porter (1986): é formado por dois subgrupos e contém 52 empresas: as vinícolas que "tentam competir em custo na produção de vinhos finos". O grupo é constituído por PMPE's, com massa crítica insuficiente para levantar barreiras à entrada e competir nos níveis internacional e global. Corresponde, aproximadamente, ao arquétipo Empreendedor (EP):

\section{Propostas para o primeiro grupo:}

Proposta de Ação WO1: Adotar uma Postura Estratégica renovada e coerente de crescimento e de desenvolvimento, com ênfase na inovação gestiva, não só de produtos (estratégia de nicho em vinhos finos tranquilos de guarda), mas também de processos (Equilíbrio de Gestão) e de mercados (novos mercados, incluindo externos);

Proposta de Ação WO2: Ter mais Ambição Estratégica (aspirar a um acréscimo substancial das vendas e agir em consonância) e promover a evolução para uma cultura organizacional e uma arquitetura empresarial adequadas (definição clara de estratégias competitivas, ajustando as estruturas orgânicas às estratégias escolhidas);

Proposta de Ação WO3: Ao nível das Lógicas Estratégico-Empresariais, fazer e/ou intensificar a estratégia de Integração Vertical a montante da produção (expandir as vinhas próprias, com vista à Diferenciação em valor) e também a jusante (com canais de distribuição próprios, principalmente, investindo em marketing e na venda digital, com o objetivo de ganhar cota de mercado, não só interna, mas também externa, com menores custos, nos moldes das micro multinacionais digitais);

Proposta de Ação WO4: Sugere-se, ao nível da estratégia competitiva, competir em Enfoque (em valor). Num segundo momento, poderá competir em Diferenciação ou Liderança de Custo Total, a 
depender de um trade off que, naturalmente, exigirá um aumento considerável da massa crítica detida.

Proposta de Ação WO5: Intensificação do crescimento das empresas, evoluindo para as vias externa e mista, de forma a aumentar significativamente e mais rapidamente a massa crítica. Para tanto, precisarão abrir os capitais e diversificarem-se por meio de aquisições, fusões e/ou alianças estratégicas;

Proposta de Ação WO6: Na sequência da abertura dos capitais, importa adotar uma estratégia de negócios, a médio e longo prazo, voltada, num primeiro momento (médio prazo), para uma maior penetração nos mercados nacionais. Num segundo momento (longo prazo), diversificar a matriz produtos-mercados para a internacionalização ou globalização (produtos standardizados ou adaptados). Deve-se sinalizar que as estratégias de negócios e competitivas decorrerão de um trade off entre os modelos dos PTP (Países Tradicionalmente Produtores, da Europa) ou NPP (Novos Países Produtores, situados na América - EUA, Argentina e Chile, África - África do Sul e Oceânia - Austrália e Nova Zelândia). Se escolher o modelo estratégico dos PTP (produção diversificada e especializada), a estratégia competitiva deverá ser a Diferenciação em valor, que se fará com a abordagem ampla (origem dos lucros) dos mercados nacionais e internacionais. Se a escolha, porém, recair sobre o modelo estratégico dos NPP (produção industrial em massa), as empresas deverão competir em Diferenciação ou Custo, mas em escala global e com uma gama de produtos mais limitada, para se beneficiarem das economias de escala e de gama. Nessa situação, é essencial possuírem massa crítica e capacidades superiores àquelas estimadas para a internacionalização, de maneira a obter sinergias diversas e transferi-las para outras localidades, o que tendencialmente potencializa os resultados de uma coordenação de gestão bem articulada (PORTER, 1999); e isso exige estabelecer e dispersar globalmente as suas "bases domésticas", Ibdem, (com capacidades acrescidas das dimensões produtiva e gestiva para a competição globalizada). Entretanto, faz-se um alerta: é essencial reduzir os riscos da internacionalização ou da globalização, por meio de um sistema de inteligência de mercado eficiente, entre outros sistemas de controle. 
Proposta de Ação WO7: Buscar o "equilíbrio de prioridades" (ANSOFF, 1990) entre as classes de decisões estratégicas e operacionais.

Proposta de Ação WO8: Desenvolver o sentido da urgência estratégica, posto que o tempo é elemento crucial em ambientes dinâmicos, como é o caso do setor vitivinícola;

Proposta de Ação WO9: Analisar permanentemente a "cadeia de valor" (PORTER, 1989) para decidir em tempo útil quais atividades devem ser internalizadas ou externalizadas.

Proposta de Ação WO10: Desenvolver parcerias com fornecedores de uvas, com vista à melhoria da qualidade.

Segundo Grupo de Vinícolas: É formado, majoritariamente, por vinícolas que tentam competir em custo, produzindo vinhos indiferenciados, e também em Diferenciação e Enfoque, na produção de vinhos finos (são, tendencialmente, vinícolas de porte médio, pertencentes ao arquétipo Adaptativo - AD).

\section{Propostas para o segundo grupo:}

Proposta de Ação W01: Primeiro, é essencial fazer um trade off entre produzir vinhos indiferenciados (competição em custo) ou produzir vinhos finos (mais rentáveis). Se a escolha recair sobre os vinhos indiferenciados, terá grandes dificuldades para competir com as grandes empresas presentes no grupo de empresas Planejamento Artesanal (PA); se a escolha recair sobre os vinhos finos deve-se ter em atenção as propostas que seguem abaixo:

Proposta de Ação WO2: Para a produção de vinhos finos tranquilos sugere-se competir em Enfoque (em valor). Para tanto, deve adotar o modelo dos PTP;

Proposta de Ação WO3: Alternativamente, poderá concentrar-se no mercado de espumantes, que continua em crescimento e detém o domínio do mercado interno;

Proposta de Ação WO4: Não competir em Diferenciação, porque dificilmente uma empresa média conseguirá abarcar todos os segmentos do mercado (alvo estratégico muito amplo);

Proposta de Ação WO5: Se possível, e para aquelas vinícolas que pretendem competir em Enfoque, localizar-se no Vale dos 
Vinhedos (RGS), detentor da única Denominação de Origem do Brasil devidamente reconhecida pela União Europeia e, portanto, com potencial para competir sob o modelo dos PTP, inclusive, na vertente da internacionalização;

Proposta de Ação WO6: Adotar a via mista para o crescimento (aumenta a massa crítica mais rapidamente);

Proposta de Ação WO7: As estratégias de negócio devem privilegiar também as inovações de gestão, de processos e de produtos;

Proposta de Ação WO8: Intensificar o marketing e investir em pontos de vendas virtuais (internet);

Proposta de Ação WO9: Ao nível da "Hierarquia de Objetivos" (ANSOFF, 1990), tanto o quanto possível, optar por objetivos financeiros de prazo alargado, privilegiando a sustentabilidade e rentabilidade dos investimentos, para conferir maior capacidade de resposta estratégica aos movimentos ofensivos da concorrência;

Proposta de Ação WO10: Tanto quanto possível, investir na integração vertical a montante (produzir as próprias uvas), principalmente no caso de competição em Enfoque;

Proposta de Ação WO11: Desenvolver também o sentido da urgência estratégica, dado que o tempo é elemento crucial em ambientes dinâmicos, como é o caso do setor vitivinícola;

Proposta de Ação WO12: Investir na busca do "equilíbrio de gestão", com ênfase na gestão estratégica, mas sem descuidar a gestão corrente;

Proposta de Ação WO13: Analisar também permanentemente a "Cadeia de Valor" para decidir em tempo útil quais atividades devem ser internalizadas ou externalizadas;

Proposta de Ação WO14: Desenvolver também parcerias com fornecedores de uvas, com vista à melhoria da qualidade.

Terceiro Grupo de Vinícolas: Compete em custo, produzindo, majoritariamente, "vinhos indiferenciados", embora também produza "vinhos finos" e "outros derivados da uva e do vinho". É formado por vinícolas pertencentes ao arquétipo Planeamento Artesanal - PA (as maiores do setor). 


\section{Propostas para o terceiro grupo:}

Proposta de Ação WO1: Preparar as empresas para que abram os capitais (médio prazo) e crescer por meio da via mista, com foco nos mercados interno e internacional;

Proposta de Ação WO2: Consolidação no mercado interno em termos de vinhos finos tranquilos (médio prazo);

Proposta de Ação WO3: Internacionalizar-se (a médio e/ou longo prazo);

Proposta de Ação WO4: A estratégia de negócio deve incluir também inovações de gestão, de processos, de produtos e de mercados;

Proposta de Ação WO5: Ao nível da "Hierarquia de Objetivos", tanto quanto possível, optar por objetivos financeiros de prazo alargado, privilegiando a sustentabilidade e rentabilidade dos investimentos, para conferir maior capacidade de resposta estratégica aos movimentos ofensivos da concorrência;

Proposta de Ação WO6: Investir na integração vertical a montante (produzir as próprias uvas, com a finalidade estratégica de diferenciação dos vinhos);

Proposta de Ação WO7: Desenvolver também o sentido da urgência estratégica, posto que o tempo é elemento crucial em ambientes dinâmicos, como é o caso do setor vitivinícola.

Proposta de Ação WO8: Analisar permanentemente a "Cadeia de Valor" para decidir em tempo útil quais atividades devem ser internalizadas ou externalizadas;

Proposta de Ação WO9: Desenvolver também parcerias com fornecedores de uvas, com vista à melhoria da qualidade dessa matéria prima;

Proposta de Ação WO10: Embora não apresente problemas com o "Equilíbrio de Prioridades", é essencial manter-se atento a este aspecto.

\subsection{Limitações e pistas para investigação futura}

Pode-se apontar como uma das principais limitações deste estudo a não inclusão de todas as regiões vitivinícolas brasileiras, apesar das regiões RGS e VSF, juntas, abarcarem mais $90 \%$ da massa crítica setorial do Brasil. No entanto, há notícias de movimentações 
importantes de vinícolas que importa analisar, em São Paulo e em Santa Catarina, na produção de vinhos finos, principalmente, mas sem negligenciar os Estados do Paraná, Minas Gerais, Goiás e Ceará.

Para além disso, embora relembrando a assumida natureza exploratória do Estudo de Casos Múltiplos do Vale do São Francisco, haverá domínios que foram tratados de forma superficial necessitando, por isso, ainda de pesquisas complementares. Estarão neste caso, por exemplo, os impactos que as dinâmicas de internacionalização/ globalização do setor vitivinícola têm provocado na forma como as cinco empresas do VSF refletem e definem os rumos da estratégia a ser seguida e da estrutura orgânica a ser implementada.

Para as duas regiões estudadas também encorajamos a realização de estudos sobre as fontes de vantagens competitivas de localização, notadamente, naquilo que se refere a: (i) Quantidade e custo dos fatores (recursos naturais, humanos, de capital, infraestruturas físicas, administrativas, de informação, científica e tecnológica); (ii) Qualidade e especialização dos fatores; (iii) Condições da procura; (iv) Fornecedores capazes, situados na localidade; (v) Setores relacionados e de apoio; (vi) Presença de aglomerados, em vez de setores isolados.

Todos estes estudos complementares consubstanciam o lançamento de uma pista robusta de investigação futura integrada: o estudo das condições para criação de um aglomerado industrial que potencie um crescimento superior do Polo Vitivinícola do Vale do São Francisco e do cluster Rio Grande do Sul, de modo a aproveitar os benefícios das estratégias relacionais, bem como do modelo de reatividade e de análise do tempo, inclusive, pela via do crescimento misto, como forma de conferir resultados sustentáveis, a prazos menores.

Será igualmente relevante fazer uma avaliação mais aprofundada das empresas, principalmente, no que diz respeito à vertente do seu desempenho econômico, se conseguirmos mais dados contábeis para o efeito. Tal estudo seria relevante para aferir, por exemplo, possibilidades de fusões e aquisições, com vista ao crescimento misto.

E, finalmente, investigações profundas sobre a Cadeia de Valor da vitivinicultura brasileira seriam muito pertinentes. 


\section{REFERÊNCIAS}

ANSOFF, I. A nova estratégia empresarial. São Paulo: Atlas, 1990.

CALORI, R.; P., VERY, P.; J.L. ARRÈGLE. Les PMI face à la planification stratégique. Revue Française de Gestion: p.11-23.1997.

CHANDLER, A. Strategy and structure. Cambridge: The MIT Press, 1962.

DRUCKER, P. F. The age of discontinuity. New York: Harper \& Row Publishers, 1968.

DESPLOBINS, G. La dynamique qualiative en viticulture: Le contre-modèle brésilien. In: ÉTIENNE, M., MONTAIGN, E., COURDEC, J-P, d'HAUTEVILLE, F. \& HANNIN, H. (coord.). Bacchus 2006: Enjeux, straégies et pratiques dans Ia filière vitivinicole. Paris: Edittions LaVigne-Dunod, 2006. cap. 10, p. 237-256.

FREIRE, A. Estratégia: Sucesso em Portugal. Lisboa: Verbo, L1997.

GALBRAITH, J. Organization design. Reading, MA: Addison-Wesley, 1977.

GALBRAITH, J. Planejamento estratégico e de organizações. In Mintzberg, H. \& Quinn, J. B (org.). O processo da estratégia, (3nd ed.). Porto Alegre: Bookman, 2001. p.133-149.

HAMEL, G.; PRAHALAD, C. K. Competing for the future. Harvard Business Review, p. 22-128, Julho-Agosto, 1994.

MAROCO, J. Análise estatística com utilização do SPSS. (3nd ed.). Lisboa: Edições Sílabo, 2007.

MINTZBERG, H. Structure et dynamique des organisations. Paris: Editions d'Organisation, 1982.

MINTZBERG, H. The fall and rise of strategic planning. In Harvard Business Review, p.107114, January-February, 1994.

MONTAIGNE, E.; COURDEC, J-P; d'HAUTEVILlE, F.; HANNIN, H. (coord.). Bacchus 2005: Enjeux, straégies et pratiques dans Ia filière vitivinicole. Paris: Edittions LaVigne-Dunod, 2005.

PESTANA, M. H., \& GAGEIRO, J. N. Análise de dados para ciências sociais: A complementaridade do SPSS. (4nd ed.). Lisboa: Sílabo, 2005.

PESTANA, M.H. \& GAGEIRO, J. N. Análise de dados para ciências sociais: A complementaridade do SPSS. (5nd ed.). Edições Sílabo. Lisboa, 2008.

PORTER, M. E. Estratégia competitiva: Técnicas para análise de indústrias e da concorrência. (16nd ed.). Rio de Janeiro: Campus, 1986.

PORTER, M. E. Competindo além das localidades: Ampliando a vantagem competitiva através de uma estratégia global. In: Competição: On compettition. Estratégias competitivas essenciais. Rio de Janeiro: Campus, 1999. Cap 9, p. 326-365.

PORTER, M. E. Vantagem competitiva: Criando e sustentando um desempenho superior. (18nd ed.). Rio de Janeiro: Campus, 1989.

RAMALHO, P. J. P. Estratégias para o desenvolvimento do sector vitivinícola brasileiro: O caso das empresas do Vale de São Francisco. Évora, 2006. 265f. Dissertação (Mestrado), Universidade de Évora, Portugal. 
RAMALHO P.J.P. Estratégias para o setor vitivinícola brasileiro, em contexto global: desenvolvimentos de gestão empresarial das empresas no Rio Grande do Sul e no vale do São Francisco. 2019. 457 p. Tese (Doutorado em Gestão de Empresas). Departamento de Economia e Gestão, Universidade de Évora, Portugal.

RAMALHO, P. J. P.; SOUSA, A. J. Globalização e estratégias para o sector vitivinícola brasileiro: O polo emergente do Vale do São Francisco. RIAE - Revista Ibero-Americana de Estratégia. São Paulo, 8, (1), p. 05-23, jan./jun. 2009.

RAMALHO, P. J. P.; SOUSA, A. J. Estratégia empresarial: Setor vitivinícola brasileiro, globalização e empresas do Vale do São Francisco. Petrolina: Printpex, 2011.

RAMOS, V. Estratégia empresarial e dinâmicas de inovação: Referências para uma gestão estratégica de sucesso no sector vitivinícola brasileiro. Évora. 2015. 326f. Tese de Doutoramento, Universidade de Évora.

SEKARAN, U.; BOUGIE, R. Research methods for business - a skill building approach. (5nd ed.). New York: Wiley and Sons, 2010.

STACEY, R. A gestão do caos. Lisboa: Dom Quixote, 1994.

SOUSA, A. Estratégias empresariais em contexto dinâmico: Lógicas de reorganização das empresas vitivinícolas do Alentejo e da Extremadura face à evolução do mercado comum europeu. Évora, 2000. 415f. Tese de doutoramento, Universidade de Évora.

VIVAS, C. Estratégias de internacionalização: contextos, formas de atuação, organização e performance das empresas vitivinícolas portuguesas. Évora, 2012. 422f. Tese de Doutoramento, Universidade de Évora.

WEIHRICH, H. The TOWS Matrix - A tool for situational analysis. Journal of Long Range Planning. Great Britain v 15, n.2, p. 54-66. 1982.

YIN, R. Estudo de caso: Planejamento e métodos. (4nd ed.). Porto Alegre: Bookman, 2010.

Recebido em: 26-8-2019

Aprovado em: 22-7-2021

Avaliado pelo sistema double blind review.

Disponível em http://mjs.metodista.br/index.php/roc 